\title{
Ionic Liquids: A Versatile Medium for Palladium-Catalyzed Reactions
}

\author{
Ram Singh,* Mukul Sharma, Ritu Mamgain and Diwan S. Rawat* \\ Department of Chemistry, University of Delhi, Delhi-110007, India
}

\begin{abstract}
Um grande número de reações de formação de ligações carbono-carbono (tais como: acoplamentos de Heck, Suzuki, Stille, Negishi e Sonogashira, entre outros) é facilitado pela catálise com compostos de paládio. Neste artigo de revisão, apresentamos uma visão detalhada e compreensiva da literatura sobre a versatilidade do uso de líquidos iônicos em conjunto com paládio em vários tipos de reações.
\end{abstract}

A number of carbon-carbon bond forming reactions in organic chemistry (such as the Heck, Suzuki, Stille, Negishi, Sonogashira coupling etc) are facilitated by catalysis with palladium compounds. An attempt has been made to present a detailed and comprehensive literature collection about the versatility of ionic liquid in conjunction with palladium for various types of reactions.

Keywords: ionic liquid, palladium catalyzed reactions

\section{Introduction}

Ionic liquids (ILs) have become a focus of increasing interest for many chemical transformations as they are non-flammable, non-volatile, highly solvating, noncoordinating and have a high thermal stability ${ }^{1-13}$ and hence a possible alternative to volatile organic solvents. ILs have made significant progress in recent years in the catalytic processes. ${ }^{14-30}$ They are liquid salts in which the ions are poorly coordinated. ILs are not simply salts dissolved in liquid but they usually exist as liquid below $100{ }^{\circ} \mathrm{C}$, or even at room temperature (room temperature ionic liquids; RTILs). ${ }^{31-33}$ In ILs generally one or both of the ions are large and the cation has a low degree of symmetry as a result they have reduced lattice energy and hence lower melting points. The first room temperature IL $\left[\mathrm{EtNH}_{3}\right]\left[\mathrm{NO}_{3}\right]$, was discovered in $1914^{34}$ but huge amount of interest was initiated only after the development of binary ionic liquids from mixtures of aluminum(III) chloride and $\mathrm{N}$-alkylpyridinium or 1,3-dialkylimidazolium chloride. Molten salts or fused salts are the other names of ILs, as used in older literature.

The main advantage of IL is to reduce or eliminate the hazards associated with volatile organic solvents. They have been used for variety of applications such as solvents for organic and catalytic reactions, new material productions,

*e-mail: singh_dr_ram@yahoo.com; dsrawat@chemistry.du.ac.in solvents for separation and extraction processes, novel electrolytes for electrochemical devices and process, enzyme catalysis/multiphase bioprocess operations, and so on. ILs are referred as 'designers solvent', and one of their most important advantages is their physio-chemical properties and the phase behavior of the systems that can be tuned/controlled by tailoring their structures. ${ }^{35-42}$

The application of ionic liquids as solvents for transition metal catalysis is an area of intense current interest, and a wide range of reactions are under investigation. Solubility of organometallic compounds increases in IL and therefore they are considered to be the best solvents for reactions with homogeneous catalysts. Based on the coordination properties of the anions, the ILs can be regarded as solvent or as a cocatalyst. ${ }^{31,43} \mathrm{ILs}$ formed by the reaction of a halide with Lewis acid generally act as a cocatalyst. In many cases, the acidity of an IL is used to convert the neutral catalyst precursor into the corresponding cationic active form. ${ }^{44,45}$

The uses of ILs in transition metal catalyzed reaction have many advantages. These solvents provide attractive alternatives to many volatile molecular solvents. The solvation properties of the IL can be adjusted by different cation/anion combinations, which allow a systematical optimization of the biphasic reaction. The selectivity in the multiphase reactions can be achieved by the preferential solubility of only one reactant in the catalyst solvent or from the in situ extraction of reaction intermediates out of the catalyst layer. ILs have been found superior solvent 
in many cases for transition metal catalyzed reactions in comparison to water or other common organic solvents especially when ionic complexes are used as catalysts. In these cases, significant enhancement of catalytic activity and stability has been observed.

The first transition metal catalyzed reactions in ILs were carried out in different ILs such as 1-butylpyridinium chloride; $[\mathrm{BuPy}] \mathrm{Cl}$ and tetrabutylphosphonium chloride; $\left[\mathrm{Bu}_{4} \mathrm{P}\right] \mathrm{Cl}$. Various nickel complexes were dissolved in these liquids and some were found to catalyze the dimerisation of alkenes. ${ }^{46,47}$ Later, many other transition metal catalyzed reactions were also carried out in ILs. Various advantages have been observed including, assisting in the activation of the catalyst, improvement of the stability of the catalyst, excellent immobilization and recyclability, facilitating product isolation and influencing the selectivity of the reaction.

The ILs are not always advantageous solvents for catalysis. One important example is the hydrogenation reaction in the presence of ruthenium clusters $\mathrm{Ru}_{3}(\mathrm{CO})_{12-\mathrm{x}}(\mathrm{tpptn})_{\mathrm{x}}(\mathrm{x}=1-3)$ and $\mathrm{H}_{4} \mathrm{Ru}_{4}-(\mathrm{CO})_{11}$ (tpptn) [where tpptn $\left.=\mathrm{P}\left(m-\mathrm{C}_{6} \mathrm{H}_{4} \mathrm{SO}_{3} \mathrm{Na}\right)_{3}\right]$ catalyze the hydrogenation of non-activated alkenes ${ }^{48}$ and the cubane $\left[\mathrm{Ru}_{4}\left(\eta^{6}-\mathrm{C}_{6} \mathrm{H}_{6}\right)_{4}(\mathrm{OH})_{4}\right]^{4+}$ catalyses the hydrogenation of benzene, ${ }^{49}$ under aqueous-organic biphasic conditions. The catalytic activity of these catalysts was also evaluated in ILs, but they found to be less effective than in the aqueousorganic medium.

In the following section, a comprehensive coverage of the literature covering the developments in the field of palladium-catalyzed reactions in ionic liquids is presented. This is because, till date, the most widely used metal for catalysis in ILs is 'palladium'. The monthly appearance of a number of papers on this topic clearly shows its importance in organic synthesis.

\section{Palladium-Catalyzed Reactions in Ionic Liquids}

The common problem associated with palladiumcatalyzed reactions forced the chemists to search a solvent like ILs. The problems include the decomposition and leaching of expensive catalytic systems, laborious product isolation, low activities and selectivities, poor reagent and catalyst solubility, and difficulties in catalyst recycling. The $\mathrm{IL}$ is often used to immobilize the palladium catalyst in an ionic phase of a biphasic reaction system, thus bridging the gap between homo- and heterogeneous catalysis and solves not all but most of the problems.

There are several reports on palladium-catalyzed reactions in ILs ${ }^{50,51}$ such as Stille, ${ }^{52}$ Suzuki,,${ }^{53}$ SonogashiraHigihara, ${ }^{54}$ Heck arylations ${ }^{55,56}$ etc.

\subsection{Heck reaction}

The palladium-catalyzed coupling between aryl halides or vinyl halides and activated alkenes in the presence of a base is referred as the Heck Reaction. ${ }^{57-61}$ This reaction received a significant attention since ever it was discovered in early 1970 `s, due to its major role in organic synthesis. Heck reaction is one of the best methods to achieve substituted alkenes, dienes, and other unsaturated structures, many of which are important intermediates in the complex natural product synthesis, and in the production of fine chemicals. ${ }^{62-65}$ However, this reaction also suffered from various limitations and hence hampered a larger industrial exploitation. ${ }^{66}$ Many modifications were done in this reaction but most of them are towards improvement of catalytic activity. ${ }^{67-71}$ In recent times, quaternary ammonium, pyridinium and imidazolium salts have been used as solvent modifications for the Heck reaction of alkenes with aryl halides. ${ }^{72-74}$

The synthesis of trans-cinnamates by the reaction of bromobenzene with butyl acrylate catalyzed by palladium salts in ILs was the first example of Heck reaction in ILs (Scheme 1). ${ }^{72}$ Tetrabutylammonium bromide (TBAB) and tributylhexadecylphosphonium bromide (TBHPB) was used as ILs and $\left[\mathrm{PdCl}_{2}\left(\mathrm{PPh}_{3}\right)_{2}\right]$ was used as a palladium source for the reaction. It was observed that the catalytic activity was present for two successive runs. This work caught the attention of several groups around the world, and then there was no dearth of publications on this topic.

The $\beta$-arylated carbonyl compounds were also prepared by Heck reaction using aryl halides and allylic alcohols catalyzed by $\mathrm{PdCl}_{2}$ in molten tetraalkylammonium bromide (Scheme 2) ${ }^{75}$ The reaction in 1-butyl-3-methyl-imidazoline hexafluoro phosphate; [bmim] $\left[\mathrm{PF}_{6}\right]$, or $N$-hexylpyridinium hexafluorophosphate; [ $\mathrm{HexPy}]\left[\mathrm{PF}_{6}\right]$ using $\mathrm{PdCl}_{2}$ as catalyst, and $\mathrm{Et}_{3} \mathrm{~N}$ or $\mathrm{NaHCO}_{3}$ as base was also performed. ${ }^{64,73,76}$ The catalyst was found to be highly soluble in ILs, allowing the isolation of the product by extraction into a non-polar organic solvent. The addition of water in the reaction mixture, leads to a triphasic system in which the salt $\left(\mathrm{Et}_{3} \mathrm{NHBr}\right)$, which is formed in the reaction was extracted into the aqueous phase. The imidazolium ionic liquids were found to have greater catalytic activity in comparison with the reactions performed in pyridinium analogues. This was attributed to the formation of palladium-carbene complexes in the former ionic liquid. ${ }^{64}$ The [bmim]Br ionic liquid was more efficient in Heck reaction of iodo or bromobenzenes having electron-withdrawing groups with styrene or acrylates than $[\mathrm{bmim}]\left[\mathrm{BF}_{4}\right]$. This is due to the formation of active carbene catalytic species. 
The Pd-catalyzed Heck reaction of an electron-rich olefin, such as 5-hexen-2-one with substituted aryl bromides in the IL $[\mathrm{bmim}]\left[\mathrm{BF}_{4}\right]$ lead to the formation of an $\gamma$-Arylated- $\gamma, \delta$-unsaturated ketones (Scheme 3$){ }^{77}$

The method is applicable to the coupling of both electron-rich and electron-deficient aryl bromides. ${ }^{77}$ This reaction was found to be highly regioselective, and it was observed that regioselectivity depends on the nature of the ligand. For example, use of 1,3-bis(diphenylphosphino) propane palladium; [Pd-DPPP] lead the formation of predominantly branched $\gamma$-arylated products, while change of ligand from DPPP to $1,1^{\prime}$-bis(diphenylphosphino) ferrocene; [DPPF] affords predominantly the $(E)$-type $\delta$-arylated $\gamma, \delta$-unsaturated ketones.

Functionalized ionic liquid network such as [bmim] [TPPMS ] and [bmim] [OAc] in presence of $\mathrm{PdCl}_{2}\left(\mathrm{CH}_{3} \mathrm{CN}\right)_{2}$ efficiently catalyzes the Heck reaction of bromobenzene with ethyl cinnamate, without the loss of catalytic activity even after eleven cycles (Scheme 4). ${ }^{78}$ The synergic ligand effects of [bmim][TPPMS] and [bmim][OAc], has lead this beneficial influences of this ionic liquid. This catalytic system is very stable as [Bmim] [OAc] acts as a base, which stops the accumulation of sodium or potassium ammonium bromide, while $[\mathrm{bmim}][\mathrm{Br}]$ inhibit the formation of Pd black.
Ultrasonic irradiation also facilitates the coupling of iodoarenes with alkenes or alkynes by $\mathrm{Pd}(\mathrm{II})$ catalyst in imidazolium ionic liquids at room temperature. ${ }^{79}$ The use of ultrasound as a way of energy source to any reaction system is known. ${ }^{80}$ The reaction of iodobenzene with ethyl acrylate using $\mathrm{Pd}(\mathrm{OAc})_{2}$ or $\mathrm{PdCl}_{2}$ as $\mathrm{Pd}$-source in [bmim] $\left[\mathrm{BF}_{4}\right]$ required heating to $90{ }^{\circ} \mathrm{C}$ for $24 \mathrm{~h}$ to get $43 \%$ yield of ethyl cinnamate. ${ }^{74}$ Ligand-less palladium catalyzed Heck reaction has been reported in biphasic systems using highmelting alkylammonium tetrafluoroborate and water or toluene as a solvent. ${ }^{81}$ This method was found to be more attractive as it not only overcomes the problem of solubility of the organic substrates but also makes the work-up and separation of the final products very simple.

The Pd-catalyst in conjunction with ionic liquid also improves reaction yields, and avoids the isomarization of many conjugated dienes. ${ }^{64}$ An appropriate selection of ionic liquid, catalyst and base can provide an efficient and straightforward route for the synthesis of $(E)$-1-aryl4-ethoxybuta-1,3-dienes from $\alpha, \beta$-unsaturated dienes and substituted aryl iodides (Scheme 5). ${ }^{64}$

Palladium-catalyzed Heck arylation of the electron-rich olefins, vinyl ethers, enamides, and allyltrimethylsilane with a wide range of aryl bromides, iodides and aryl

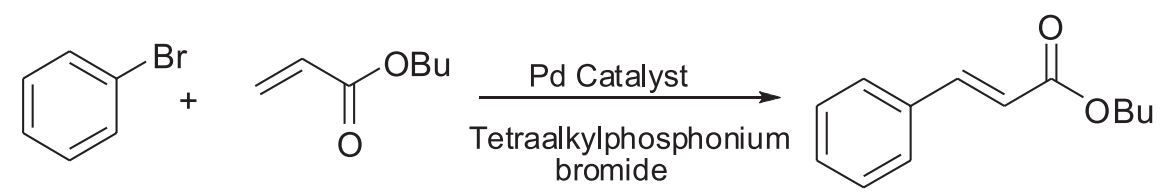

Scheme 1.<smiles>[R20]c1ccc2cc(Br)ccc2c1</smiles>

Scheme 2.<smiles>[R][R]1ccc(Br)cc1</smiles>

Scheme 3. 


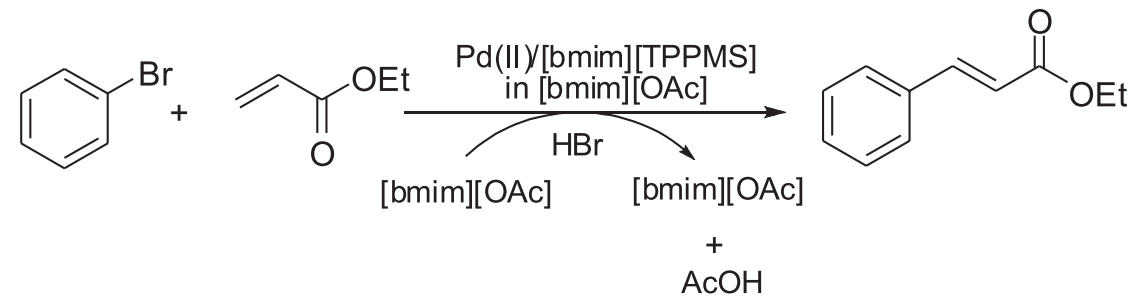

Scheme 4.
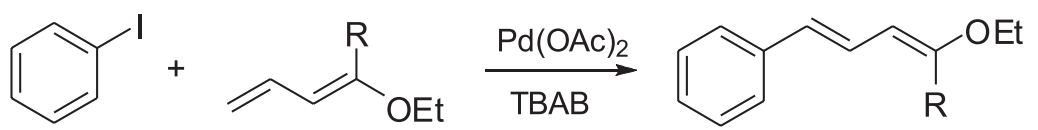

Scheme 5.

triflates, have been reported in imidazolium ionic liquids (Scheme 6). ${ }^{52}$ The reaction leads to the formation of the desired product in high regioselectivity without the need for costly or toxic halide scavengers. The reaction works well for wide variety of aryl groups of diverse electronic and steric properties at the olefin carbon. Furthermore, the arylation reaction in molecular solvents led to mixture of regioisomers under identical reaction conditions. This methodology provides a simple way for preparing branched arylated olefins using wide range of substrates.

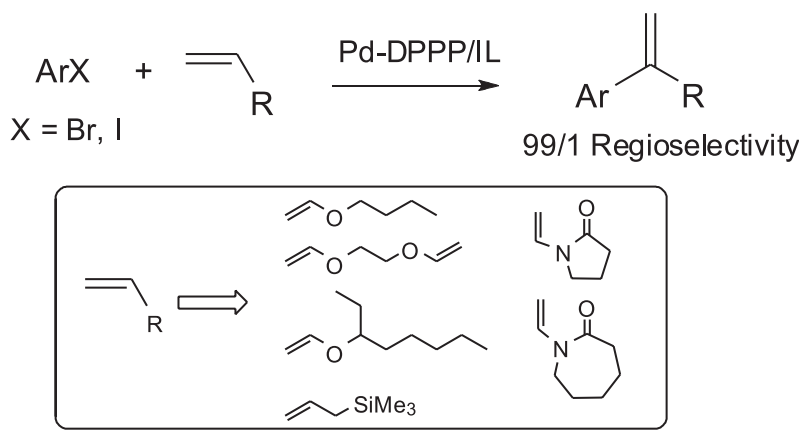

Scheme 6.

Brønsted acid-base ionic liquids based on guanidine (GILs) and acetic acid are also found to be an efficient and reusable reaction media for palladium-catalyzed Heck reactions. These solvents play a dual role such as strong bases and as ligands to stabilize Pd species (Scheme 7) ${ }^{82}$ The Mizoroki-Heck arylation of alkenes have high synthetic utility. ${ }^{83-85}$ Aryl chlorides and alkenes can be coupled under decarbonylative conditions. ${ }^{86}$ The readily available sulfonyl chlorides $\left(\mathrm{RSO}_{2} \mathrm{Cl}\right)$ are found to be more reactive than corresponding bromides and chlorides. ${ }^{87,88}$ The ionic liquid, $N$-butyronitrile pyridinium bis(trifluoromethylsulphonyl) imide (1) together with $\mathrm{PdCl}_{2}$ was used for the reaction of aryl and alkenyl sulphonyl chloride with mono- and

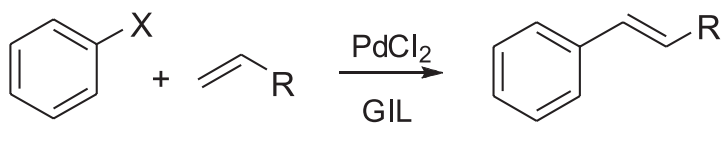

Scheme 7.

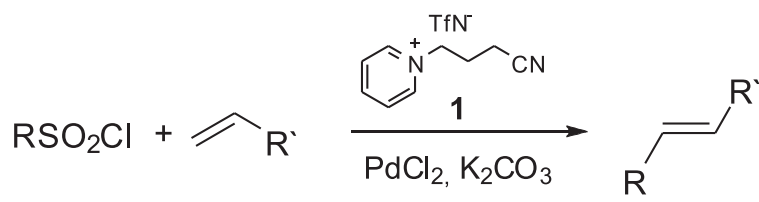

Scheme 8.

disubstituted olefins (Scheme 8) ${ }^{89}$ Palladium acetate immobilized on amorphous silica with the aid of an ionic liquid, $[\mathrm{Bmim}]\left[\mathrm{PF}_{6}\right]$ was found to be highly efficient catalytic system for the Mizoroki-Heck reaction without ligand in $n$-dodecane. The catalytic system can be recycled and reused for at least six times, in 89 98\% yields..$^{90}$

Hierso et al. ${ }^{91}$ have shown the alkynylation of variety of functionalized aryl bromides in an ionic liquid medium. The authors found that copper-free system containing $0.5 \mathrm{~mol} \%$ of $[\mathrm{Pd}(\text { allyl }) \mathrm{Cl}]_{2}, 3 \mathrm{~mol} \% \mathrm{PPh}_{3}$ and 1.2 equiv pyrrolidine is economical, simple method of synthesis of coupled products (Scheme 9). Further these authors observed that in $[\mathrm{Bmim}]\left[\mathrm{BF}_{4}\right]$ the coupling of demanding bromides is more selective in comparison to the coupling of activated aryl bromides.

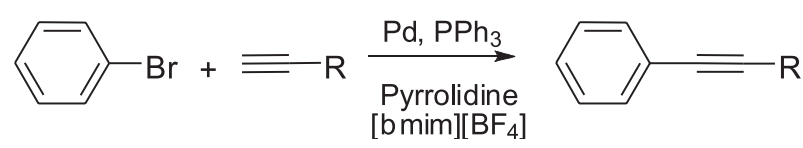

Scheme 9. 
Pd-benzothiazol-2-ylidene complex (2) catalyzes efficiently the $\mathrm{C}-\mathrm{C}$ coupling reactions of activated aryl halides with very high turnover number in the ionic liquid $\mathrm{Bu}_{4} \mathrm{NBr}$ as solvent (Scheme 10). ${ }^{22}$ The Pdbenzothiazol-2-ylidene complex was known but it did not find any application as a catalyst for Heck reaction. This complex was modified by Calo et al. ${ }^{105}$ by reaction of 3-methylbenzothiazolium iodide with palladium acetate in THF and used for Heck reactions. However, it was found less effective for reaction of the less reactive bromo or chloro aromatics, they require both higher temperature and catalyst concentration. The IL does exert a striking influence on the reactivity and the stability of the catalyst. This may be due to the formation of an anionic and more nucleophilic complex due to the presence of TBAB surrounded by large tetrabutylammonium cation that would impede, by imposing a Coulombic barrier for collision. On the other hand, IL with planar structures and poor nucleophilic anions are not efficient in influencing the reactivity and stability of the catalyst. ${ }^{22}$

The reaction of 2-methylprop-2-en-1-ol with a range of aryl halides under homogeneous and heterogeneous catalyst system in organic solvents and IL has been reported. ${ }^{92}$ In particular, the formation of 3-(4-t-butylphenyl)-2methylpropanal ( $\beta$-Lilial) has been examined in detail (Scheme 11). $\beta$-Lilial is in an intermediate of fenpropimorph (Corbel, a biodegradable fungicide) and it has also been used as fragrance and fragrance intermediate.
More recently Meunier et al. ${ }^{93}$ reported Heck alkynylation (copper-free Sonogashira coupling) of aryl halides using various metallic precursors, tertiary phosphanes and bases in $[\mathrm{Bmim}]\left[\mathrm{BF}_{4}\right]$ as the solvent. This method allows the coupling of a variety of substrates, activated or deactivated bromides in ILs. The combination of $\left[\mathrm{Pd}\left(\eta^{3}-\mathrm{C}_{3} \mathrm{H}_{5}\right) \mathrm{Cl}\right]_{2} / \mathrm{PPh}_{3}$ at only $1 \mathrm{~mol} \%$ loading with pyrrolidine as the base and in the absence of a copper salt has been found very efficient. This catalytic system worked well for sterically and electronically deactivated bromides bearing different functional groups to aryl- and alkyl acetylenes.

Traditional Heck cross-coupling reaction is a two-step process viz, halogenations and coupling, and each step is conducted independently. An effort has been made to develop a one-pot approach, that the halogenations and Heck coupling reactions can both be conducted in ionic liquid without the isolation of halogenated intermediate (Scheme 12). ${ }^{94}$ This methodology proved that this approach works well for moderately to highly electronrich aromatics.

New type of palladium(II) complex from a pyrazolylfunctionalized hemilabile NHC has been reported, and the Pd(II) complex not only exhibits high degree of stability but found to be an efficient catalyst precursor for Heck and Suzuki cross-coupling reactions in ILs (Scheme 13). ${ }^{95}$ The catalytic system can also be recovered and recycled at least three times without significant loss in catalytic activity.

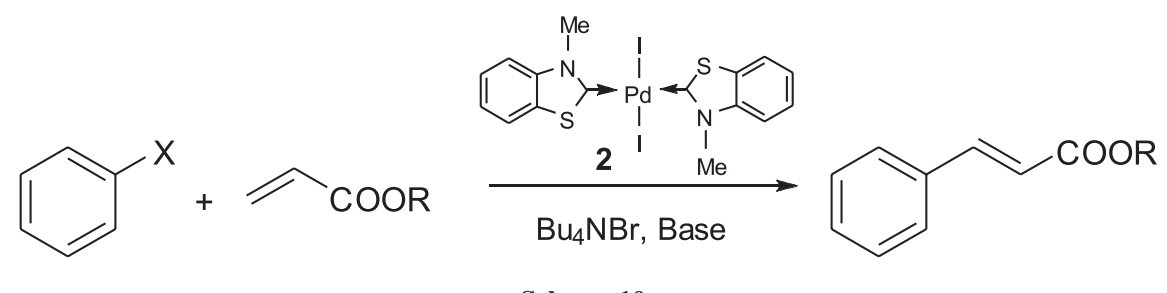

Scheme 10.<smiles>C=CC(C)OC(C)C(C)NCC(C)Cc1ccc(C(C)(C)C)cc1</smiles>

Scheme 11.

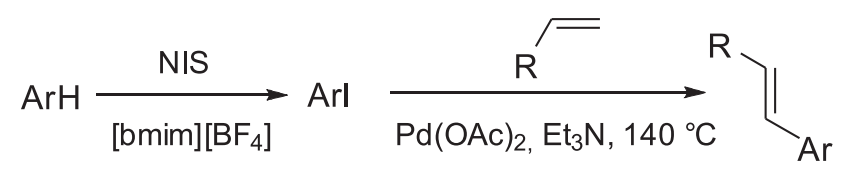


<smiles>[R]C=Cc1ccc([R])cc1</smiles>

Scheme 13.

The electron-rich vinyl ethers can be arylated by aryl bromides in a molecular solvent/ionic liquid cocktail with no compromise on regioselectivity. ${ }^{96}$ The arylation of vinyl ethers by the aryl bromides in presence of small amount of $[\mathrm{bmim}]\left[\mathrm{BF}_{4}\right]$ added to dimethyl sulphoxide (DMSO) affords only the $\alpha$-arylated products (Scheme 14). The enamide underwent similar regioselective arylation in the solvent cocktail. In the absence of the ionic liquid, lower regioselectivities were observed. This method is particularly interesting as it reduces the volume of ILs used, and also provides a simpler and more practical synthetic pathway for preparing arylated vinyl ethers and aryl methyl ketones. An elegant comparative study has been done for the palladium-catalyzed Heck reactions of heteroaryl halides such as halopyridines, bromoquinoline and bromothiophenes, with the electron-rich olefins vinyl ethers and allyl alcohol in IL, and molecular solvents (Scheme 15). ${ }^{97}$ It has been observed that in imidazolium ionic liquid essentially only the branched olefins were formed, whereas in molecular solvents a mixture of regioisomers was formed. This method also works well for aryl triflates and stoichiometric inorganic salt additives, providing an easy entry to functionalized heteroaromatics incorporating acetyl and 2-allyl alcohol functionalities.

Heck coupling reaction has also been reported in PEGsupported IL $[\mathrm{PEGmim}][\mathrm{Cl}] .^{98}$ The reaction of both aryl bromides and activated aryl chlorides with olefins using the $\mathrm{Pd}(\mathrm{OAc})_{2} /[\mathrm{PEGmim}][\mathrm{Cl}]$ system, leads the formation of coupled products in excellent yields (Scheme 16). Furthermore, the catalytic system could be recycled five times without

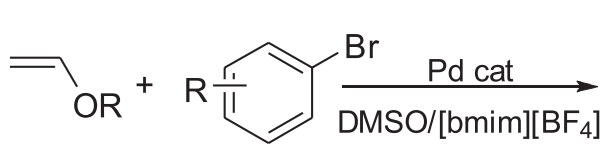<smiles>[R][I+]C[R]OC(=C)c1ccccc1</smiles>

Scheme 14.<smiles>C=COC=Cc1ccncc1</smiles>

Scheme 15.

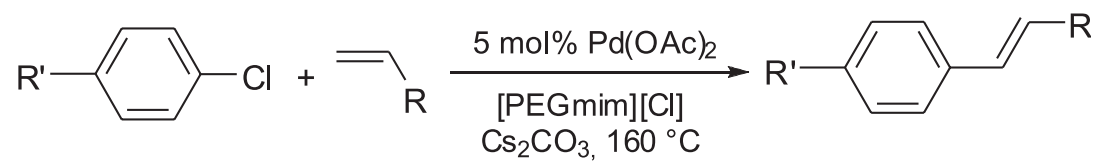

Scheme 16. 
any loss in the catalytic activity. Palladium-catalyzed Heck arylations in IL $[$ bmim $]\left[\mathrm{PF}_{6}\right]$, under microwave irradiation has been reported for the first time in 2002 (Scheme 17). ${ }^{99}$ The coupling reactions were efficiently completed within 5-45 min of heating and phosphine-free ionic catalyst phase could be recycled and reused. The product was easily isolated from the reaction mixture by distillation.

A facile methodology to accelerate Pd/C-catalyzed Heck reaction in ionic liquid by using microwave irradiation has been developed (Scheme 18). ${ }^{100}$ The main advantage of this methodology is the catalytic system can be recycled, reused and the green character of ionic liquids, and reaction takes less time to complete. A new series of Pd(II) catalyst (3) have been prepared in which $\mathrm{Pd}(\mathrm{II})$ complexes having bisimidazole-like ligands were prepared. These new catalysts proved to be very effective for the Heck reaction under phosphine-free conditions using ILs as solvents. ${ }^{101}$ The catalyst found to be sufficiently soluble in ionic liquids, and recycled five times without any loss of catalytic activity.

Heck olefination of electron-poor and electron-rich chloroarenes in no aqueous ionic liquids (NAIL) in the presence of ligand-free heterogeneous layered double hydroxide supported nanopalladium ( $\mathrm{LDH}-\mathrm{Pd}^{0}$ ) catalyst using the basic LDH exhibits higher activity and selectivity in the comparison to the no aqueous ionic liquids (NAIL) over the homogeneous $\mathrm{PdCl}_{2}$ system (Scheme 19). ${ }^{102}$ Microwave irradiation accelerates the rate of the Heck olefination reaction manifold in the case of both electronpoor and electron-rich chloroarenes. It was found that the basic $\mathrm{LDH}-\mathrm{Pd}^{0}$ shows better catalytic activity over a range of supported catalysts, from acidic to weakly basic $\mathrm{Pd} / \mathrm{C}, \mathrm{Pd} / \mathrm{SiO}_{2}, \mathrm{Pd} / \mathrm{Al}_{2} \mathrm{O}_{3}$, and resin- $\mathrm{PdCl}_{4}{ }^{2-}$ in the Heck olefination of deactivated electron-rich compounds such as 4-chloroanisole. This catalytic $\left(\mathrm{LDH}-\mathrm{Pd}^{0}\right)$ system was extended to other Pd catalyzed reactions such as Suzuki, Sonogashira, and Stille coupling reactions. The mechanistic studies of this reaction indicate that the reaction proceeds on the surface of the nanopalladium particles of the heterogeneous catalyst.

The reaction of trans-ethyl cinnamate with aryl halide in presence of $\mathrm{Pd}$ nanoparticle in TBAB leads to the formation of product in high stereoselectivity, while same reaction without the use of IL fails to give the stereoselectivity (Scheme 20). ${ }^{103}$ Palladium nanoparticles<smiles>[R]c1ccc([X])cc1</smiles>

Scheme 17.

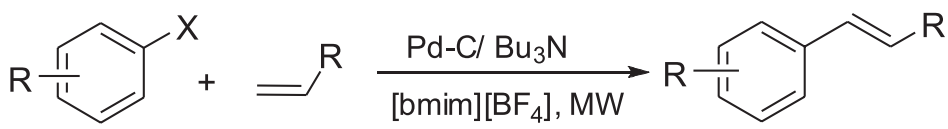

Scheme 18.

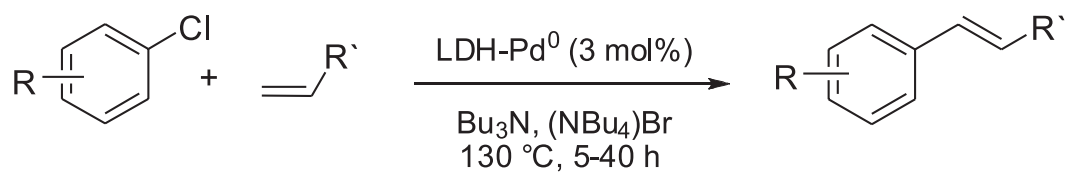

Scheme 19.<smiles>CCOC(=O)C=Cc1ccccc1</smiles>

Scheme 20. 
have been synthesized by the reaction of the $\mathrm{Pd}(\mathrm{OAc})_{2}$, with tetrabutylammonium acetate (TBAA) dissolved in TBAB, and the resulting nanoparticles efficiently catalyze the stereospecific reaction of cinnamates with aryl halides to yield $\beta$-arylsubstituted cinnamic esters in good yield. The role of TBAA was important in determining the formation of the nanoparticles and the stereospecificity of the $\mathrm{C}-\mathrm{C}$ coupling process. The stereospecificity in the presence of Pd-nanoparticles depends on the solubility of TBAA in TBAB, since other soluble bases such as amines did not increase the stereospecificity of the process. Although not proved experimentally, it is anticipated that acetate anions might participate in the fast elimination step and both ionic liquid as well as the base play an important role in determination of reaction rate and stereospecificity of the coupled product. The coupling of styrene or unsubstituted acrylates with aryl bromides catalyzed by $\mathrm{Pd}(\mathrm{OAc})_{2}$ in dimethylacetamide or dimethylformamide as a solvents results much lower yield of the product. ${ }^{104,105}$

$\operatorname{Pd}(0)$ nanoparticles ( $2 \mathrm{~nm}$ diameter $)$, immobilized in [bmim] $\left[\mathrm{PF}_{6}\right]$, found to be an efficient catalyst precursors for coupling of aryl halides with $n$-butylacrylate. ${ }^{106}$ TEM analysis of the in situ ionic liquid catalytic system shows the formation of larger nanoparticles $(\sim 6 \mathrm{~nm})$. The palladium content in the organic phase during the arylation reaction and metal leaching (up to 34\%) from the ionic phase to the organic phase at low substrate conversion was observed. Heck reaction of aryl iodides and activated aryl bromides catalyzed by copper bronze in TBAB as solvent and tetrabutylammonium acetate (TBAA) as base as been developed. The effective catalysts in this reaction are $\mathrm{Cu}$ nanoparticles derived from the reaction of iodobenzene with copper bronze. These nanoparticles are found to be very stable in tetraalkylammonium salts, can easily be recycled, and stored for months without a loss of catalytic activity. ${ }^{107}$ The Pd-nanoparticles was found to be much more efficient in TBAB than in pyridinium, phosphonium and imidazolium ILs in catalyzing the Heck reactions.

\subsection{Suzuki coupling}

Coupling of aryl- or vinyl-boronic acid with arylor vinyl halide catalyzed by a palladium(0) complex is known as Suzuki coupling. It is one of the widely studied reaction, and has been extensively used for the synthesis of poly-olefins, styrenes, and substituted biphenyls (Scheme 21). ${ }^{108-111}$ The cross coupling reactions have been studied in a range of ionic liquids at ambient temperature. ${ }^{12}$ The bromoarenes react very fast in ILs and isolation of product is very easy. The preferred reaction conditions as well as affect of changing the ionic liquid components have been investigated. The in situ formation of mixed phosphine/imidazolylidene palladium complexe is demonstrated in all of the catalytically active solutions, but not in the inactive solutions. ${ }^{13-116}$

The reaction of bromobenzene with phenylboronic acid under conventional Suzuki conditions gave $88 \%$ yield in $6 \mathrm{~h}$, while same reaction in $[\mathrm{bmim}]\left[\mathrm{BF}_{4}\right]$ gave $93 \%$ yield of the desired product in 10 minute with high turn over number (Scheme 22). ${ }^{113,114}$ The product was extracted using diethyl ether, while the by-products were removed by washing with excess water. After the work up of the reaction, the ionic

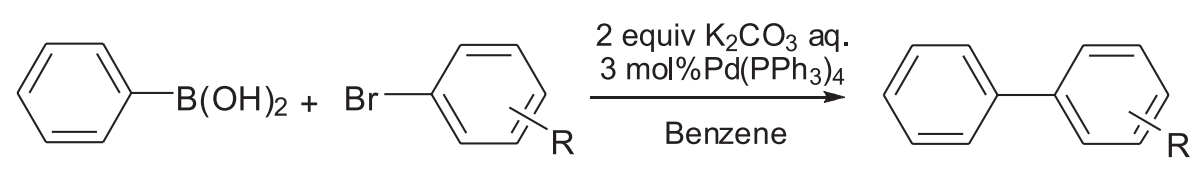

Scheme 21.
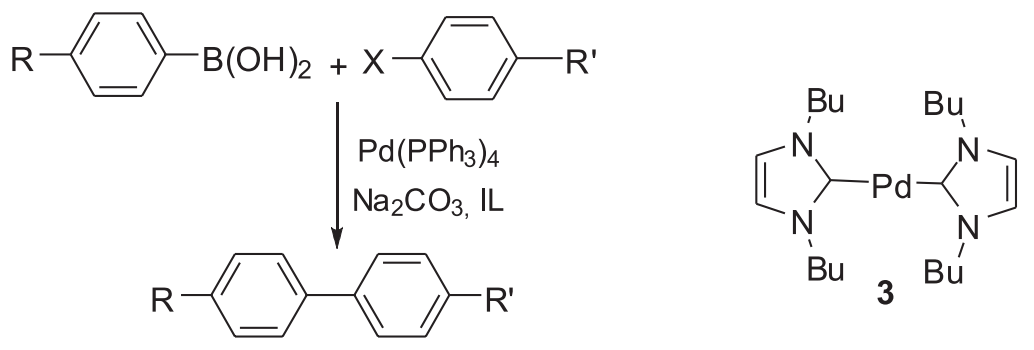

Scheme 22. 
liquid/catalyst system was reused for three times with no decrease in the yields or turn over numbers.

Suzuki coupling of various aryl halides with phenylboronic acid in the presence of palladium-bis(carbene) complexes dissolved in 1,3-di-n-butylimidazolium tetrafluoroborate [bbim] $\left[\mathrm{BF}_{4}\right]$ under ultrasound conditions are reported to form the desired product even at room temperature. ${ }^{117,118}$ The substituted chlorobenzenes which generally do not undergo Pd catalyzed coupling unless it is activated, reacts with phenylboronic acid at ambient temperature $\left(30{ }^{\circ} \mathrm{C}\right)$ in IL $\left[\right.$ bbim] $\left[\mathrm{BF}_{4}\right]$ under ultrasonic irradiation. ${ }^{118}$ The sonochemical reactions were carried out in a thermostated ultrasonic cleaning bath of frequency $50 \mathrm{kHz}$ (Branson 5200). Since the phenylboronic acid was insoluble in the IL under the reaction conditions, the sonochemical reaction was performed in the IL with methanol as cosolvent, which resulted in a homogeneous solution and complete conversion. The IL recovered in its pure form could be recycled several times. However, the main disadvantage of this reaction is the formation of inactive Pd black which prevents the recycling of the expensive palladium catalyst. But, recycling of the catalyst is possible if Pd-biscarbene complex (3) is used as a catalyst. ${ }^{118}$ The recovered complex was further used three times for the sonochemical Suzuki reaction of 4-methoxybromobenzene to afford the 4-methoxybiphenyl in $82 \%, 80 \%$ and $75 \%$ yields respectively.

Cross-coupling of aryl boronic acids with aryl halides, including aryl chlorides, worked well in the phosphonium salt ionic liquid (tetradecyltrihexylphosphonium chloride, THPC) under mild conditions and no homo-coupled products were obtained. ${ }^{119}$ The reaction proceeded well in THPC using various mild bases but potassium phosphate and water (added for salt solubility) were found to be the best base for this system. Addition of small amount of toluene helped in complete solubility of both the boronic acid and aryl halide in the ionic liquid. Complete conversion of aryl iodides, bromides and even in case of electron deficient chlorides in the THPC at $50-70{ }^{\circ} \mathrm{C}$ was achieved, indicating that a very active catalyst was produced in the THPC system. ${ }^{119}$ This catalytic system can be reused for many times, indicates that the catalytic system is highly stable in the reaction conditions.

Use of number of di- and monoquaternized 2,2`-biimidazolium-based ILs (4,5) (Scheme 23) including polyfluoroalkylated, in Suzuki-cross coupling reaction have also been studied.$^{53}$ Majority of the monoquaternary products are RTILs. The 1,3,1`-tributyl-2,2`-biimidazolium hexafluorophosphate, a monoquaternary RTIL, was found to be very efficient and recyclable solvent for the cross coupling reactions. Due to its coordination ability, the monoquaternary IL markedly avoids palladium leaching in recycling experiments. ${ }^{53}$ Organic solvent nanofiltration have been used to separate the product from both catalyst and ILs in some cases. ${ }^{120}$ All the ILs screened showed positive effects on the catalytic stability, significantly reducing the formation of palladium black and providing high reaction yields over consecutive recycles.

Very recently an air-stable and highly efficient $\mathrm{PdCl}_{2}$ $[\mathrm{Dppc}]\left[\mathrm{PF}_{6}\right]-[\mathrm{bmim}]\left[\mathrm{PF}_{6}\right]$ catalytic system has been developed for the Suzuki coupling reaction of various aryl bromides with phenylboronic acid. ${ }^{121}$ The catalytic system can be recycled at least ten times with marginal loss of catalytic activity. Palladium nano particles stabilized by tetraalkylammonium salts bearing long alkyl chains, have been proved to be an efficient catalytic system in C-C bond forming reactions such as the Suzuki and Stille cross-coupling reactions (Scheme 24). ${ }^{122}$ Use of tetrabutylammonium hydroxide as a base in Suzuki coupling, enhanced the catalyst activity, and as a result the reactions proceeded smoothly under relatively mild conditions. In addition, the catalytic system can be recycled a number of times, and reused without loss of catalytic activity.<smiles>[R]n1ccnc1-c1nccn1COc1cnc(-c2ncc[nH]2)[nH]1</smiles><smiles></smiles>

Scheme 23. 


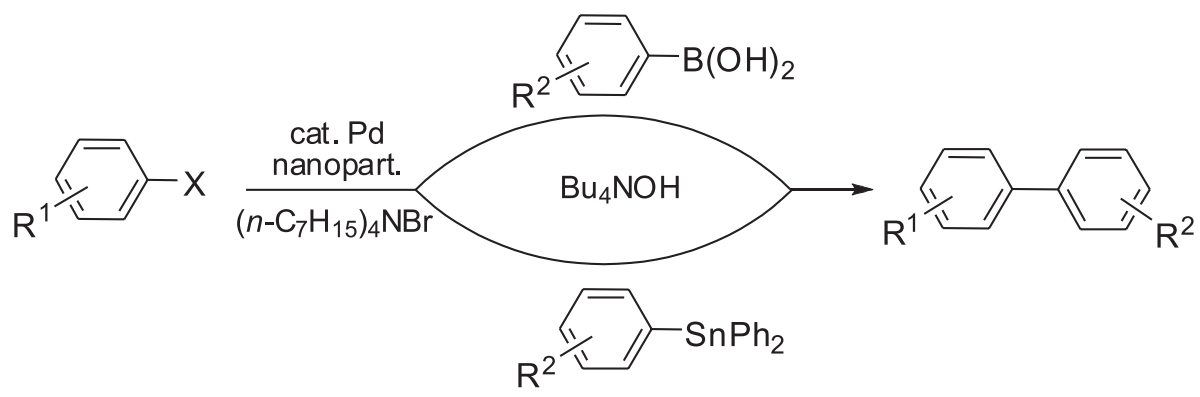

Scheme 24 .

Suzuki cross-couplings of nitrogen containing heterocyclic chlorides with naphthalene boronic acids in the ionic liquids lead to the formation of the desired product in excellent yield (Scheme 25). ${ }^{123}$ The reaction in ionic liquid found to be advantageous in comparison with the conventional organic solvent as products with good purity and higher yield were obtained with shorter reaction time. The isolation of product was simple and the ILs could be reused.

$\mathrm{N}$-Butyronitrile pyridinium cation $\left[\mathrm{C}_{3} \mathrm{CNpy}\right]^{+}$based ionic liquids have been prepared and evaluated in Suzuki and Stille coupling reactions. ${ }^{124}$ Depending on the nature of the anion, these salts react with palladium chloride to form complex of the formula $\left[\mathrm{C}_{3} \mathrm{CNpy}\right]_{2}\left[\mathrm{PdCl}_{4}\right]$ or complexes of the formula $\left[\mathrm{PdCl}_{2}\left(\mathrm{C}_{3} \mathrm{CNpy}\right)_{2}\right]$ [anion $]_{2}$. The catalytic activity of these palladium complexes was studied after immobilization in both $N$-butylpyridinium and nitrile-functionalized ILs. All of the palladium complexes show good catalytic activity, but recycling and reuse are considerably superior in the nitrile-functionalized ionic liquid. Palladium nanoparticles have been identified as the active catalyst in this coupling reactions. ${ }^{124}$

Substituted imidazoles on complexation with palladium(II) sources in ionic liquids, provides a robust air- stable system for Suzuki coupling reactions. ${ }^{125}$ Initiation of the catalytic system prior to the reaction, in the ionic liquid is essential for a successful Suzuki reaction. The catalytic system was obtained by heating the palladium source with the imidazole in the ionic liquid. Without initiation, low yield of the product was obtained with the decomposition of catalytic system. The nature of the imidazole ligands, anion and cation of the ionic liquid controls the catalytic activity. The $\left(\mathrm{CH}_{3} \mathrm{CN}\right)_{2} \mathrm{PdCl}_{2} /[\mathrm{bmim}]$ catalytic system

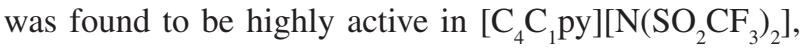
$\left[\mathrm{C}_{4} \mathrm{C}_{1} \mathrm{C}_{1} \mathrm{im}\right]\left[\mathrm{BF}_{4}\right]$. However catalyst decomposition was observed in the molecular solvents.

Suzuki coupling was also achieved in IL supported synthesis (ILSS) in which ionic liquid was supported by iodobenzoate compounds (4-iodophenol immobilized on a polystyrene-Wang resin) and gets reacted with arylboronic acids in aqueous media. Biaryl compounds were obtained in good yield and high purities after cleavage of the solid support with ammonia in methanol (Scheme 26). ${ }^{126,127}$

\subsection{Stille coupling}

The Stille coupling is a versatile $\mathrm{C}-\mathrm{C}$ bond formation reaction between organo stannanes and halides or pseudo<smiles>[R]O[Ga]c1ccccc1</smiles>

Scheme 25.

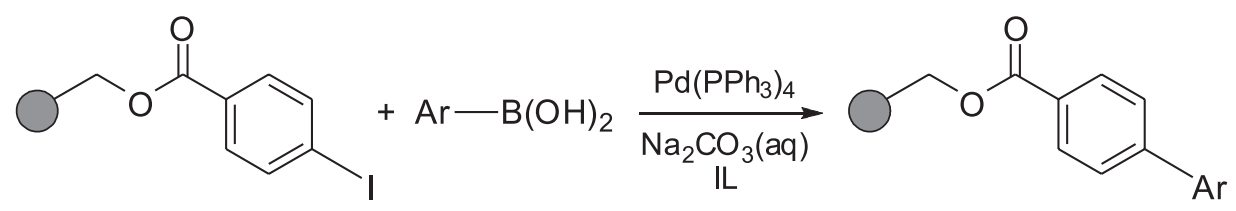

Scheme 26. 
halides (Scheme 27). ${ }^{128}$ The main disadvantage of this reaction like all transition metal-catalyzed cross coupling reactions is the use of expensive catalyst and need for expensive and/or toxic ligands. The use of palladium complexes immobilized in ILs offers great advantages over the classical organic solvents used for Stille coupling reactions. The relative strengths of the coordinating power of the cations and anions of ILs strongly affect the efficiency of the Stille cross-coupling reactions. ${ }^{129,52}$ It has been established that the nitrogen-containing anions like $\left[\mathrm{Tf}_{2} \mathrm{~N}\right]^{-}$ and $\left[\mathrm{N}(\mathrm{CN})_{2}\right]^{-}$ensure the highest reactivity, and facilitate a ligandfree reaction protocol. Also, the introduction of a nitrile-functionality onto pyridinium-based ILs reduces catalyst leaching, and improves catalyst stability. ${ }^{129}$

$$
\mathrm{RX}+\mathrm{R}^{\prime} \mathrm{SnBu}_{3} \stackrel{\mathrm{Pd} \text { cat. }}{\longrightarrow} \mathrm{R}-\mathrm{R}^{\prime}+\mathrm{Bu}_{3} \mathrm{SnX}
$$

Scheme 27.

A series of nitrile-functionalized imidazolium salts were reacted with $\mathrm{PdCl}_{2}$, resulting in the formation of salts containing a tetrachloropalladate dianion or compounds in which the nitrile substituent coordinates to the palladium center. ${ }^{130}$ Further derivation of the latter compounds affords carbenes. The catalytic activity of the different palladium salts was evaluated in Stille reactions and also in Suzuki and Heck reactions with some of the nitrile-functionalized ILs and compared with that of nonfunctionalized ILs. ${ }^{130} \mathrm{In}$ some instances, palladium nanoparticles was identified, but the nature of the catalyst strongly depends on the IL employed.

A number of Stille coupling reactions with $\operatorname{Pd}(0)$ or $\mathrm{Pd}(\mathrm{II})$ catalyst and in presence of $\mathrm{Ph}_{3} \mathrm{As}$ and $\mathrm{CuI}$ has been demonstrated in $[\mathrm{bmim}]\left[\mathrm{BF}_{4}\right]$ (Scheme 28). ${ }^{131}$ The main advantage of this methodology is the extensive recycling of the solvent and catalyst without significant loss in the catalytic activity. Furthermore, an interesting selectivity for aryl bromides and iodides was noted.

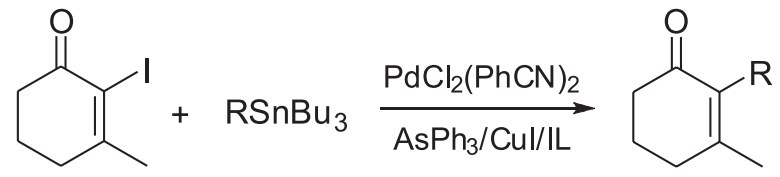

Scheme 28 .

Stille coupling reaction was investigated in different ILs in order to understand the role of different physico-chemical properties of the medium in the transfer of vinyl or alkyl groups. ${ }^{52,132,133}$ The possibility of working in the absence of ligand was evaluated. The Stille coupling of aryl iodide with vinyl and alkyl stannanes were performed in various ionic liquids (Scheme 29), which have different physico-chemical properties according to the nature of the anion and cation. The reaction of tributylvinylstannane, tetramethylstannane and tetrabutylstannane with iodobenzene in presence or in absence of $\mathrm{AsPh}_{3}$ ("ligandless" coupling) was also performed. ${ }^{52}$ When $\mathrm{AsPh}_{3}$ was present, $\mathrm{Pd}_{2}(\mathrm{dba})_{3}$ was the source of catalyst; otherwise $\mathrm{Pd}(\mathrm{OAc})_{2}$ was used in the ligandless reaction. The ligandless Stille coupling was significantly less effective, in comparison to the reaction with $\mathrm{AsPh}_{3}$ complexed catalyst, in all ILs. When nucleophilic ILs were used as solvents in the coupling of tributylvinylstannane and iodobenzene in presence of $\mathrm{AsPh}_{3}$, only low to moderate yields of product were obtained. Non-nucleophilic salts gave uniformly better results, showing that the anion has a great influence on the outcome of the reaction. ${ }^{52}$

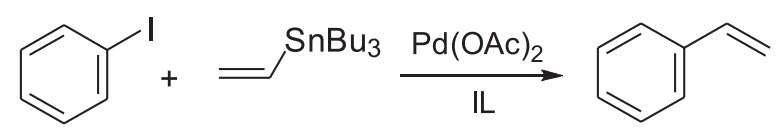

Scheme 29.

A low viscosity IL [bmim] $\left[\mathrm{NTf}_{2}\right]$ has been used as a reaction medium in Pd-catalyzed Stille and Suzuki-Miyaura coupling reactions and yield of the resulting product was found to be better than those reported previously for high viscosity ionic liquids, such as $[\mathrm{bmim}]\left[\mathrm{PF}_{6}\right]$ and [bmim] $\left[\mathrm{BF}_{4}\right] \cdot{ }^{134}$

\subsection{Negishi coupling}

First discovered in 1977, the Negishi coupling is a cross coupling reaction in organic chemistry which involved an organozinc compound, an organic halide and a nickel or palladium catalyst to create a new C-C covalent bond. Initially this reaction was used for the preparation of unsymmetrical biaryls in good yields (Scheme 30). ${ }^{135-137}$ However, over the period of time, this reaction has been used for the coupling of organozinc compounds with various halides such as aryl, vinyl, benzyl, or allyl, and is not restricted only to the formation of biaryls.

This reaction has also been achieved in IL. The reaction between aryl- or benzylzinc halides and various aryl halides was achieved smoothly in a biphasic IL/Toluene system

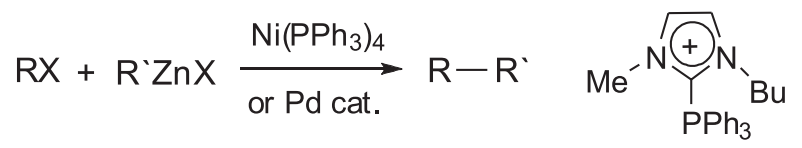

Scheme 30. 
using bis(dibenzylideneacetone)palladium, [Pd(dba) $\left.{ }_{2}\right]$ $(2.0 \mathrm{~mol} \%)$ and an ionic phosphine $6(4.0 \mathrm{~mol} \%)$ giving $70-92 \%$ yield. ${ }^{138}$ This reaction works with a variety of aryl and benzylzinc halides but only aryl halides can be uses as electrophilic partner. Aryl iodide gave the fastest result. The phosphine 6 was prepared by the reaction of $\mathrm{PPh}_{2} \mathrm{Cl}$ with [bmim] $\left[\mathrm{PF}_{6}\right]$ using butyl lithium. The use of IL makes the work up remarkable simple. The IL phase containing the palladium catalyst is separated by decantation of the toluene phase, which is submitted to the usual work-up procedure. Attempts to reuse the palladium catalytic system show that after the third cycle, a significant decrease in yield is observed (20\% lower yield and triple reaction time). ${ }^{138}$

\subsection{Trost-Tsuji reactions}

Tsuji-Trost reaction is the palladium-catalyzed allylation of nucleophiles such as active methylenes, amines, enolates and phenols with allylic compounds like allyl acetates and allyl bromides (Scheme 31). ${ }^{139-143}$ This reaction has also been performed in both mono- and biphasic ionic liquids, using $\mathrm{Pd}(\mathrm{OAc})_{2}-\mathrm{PPh}_{3} / \mathrm{K}_{2} \mathrm{CO}_{3}$ in $[\mathrm{bmim}]\left[\mathrm{BF}_{4}\right]^{144}$ and $\mathrm{PdCl}_{2}$-triphenylphosphine trisulphonate, sodium

$$
\begin{aligned}
& \mathrm{NuH}+=^{\mathrm{X}} \underset{\mathrm{THF}, \mathrm{RT}}{\stackrel{\mathrm{Pd}\left(\mathrm{PPh}_{3}\right)_{4}}{\longrightarrow}}=^{\mathrm{Nu}} \\
& X=\mathrm{OAc}, \mathrm{Br}, \quad \mathrm{NuH}=\mathrm{RNH}_{2}, \mathrm{ArOH}, \mathrm{RSH}, \\
& \mathrm{OCO}_{2} \mathrm{Me} \\
& E W G \smile E W G
\end{aligned}
$$

salt; $\left[\mathrm{PdCl}_{2}\right.$-TPPTS $]$, and in $[\mathrm{bmim}][\mathrm{Cl}] /$ cyclohexene respectively (Scheme 32). ${ }^{145}$ Ten-fold enhancement of catalytic activity was observed in the biphasic ionic liquid system in comparison to the aqueous reaction conditions. Furthermore, the reaction in biphasic ionic liquid conditions showed a significant improvement in the selectivity, since the formation of cinnamyl alcohol and phosphonium salt was suppressed in ILs. ${ }^{145}$

An efficient microwave assisted Tsuji-Trost reaction was also developed for allylic substitution with various carbon and heteronucleophiles catalyzed by $\mathrm{Pd}(\mathrm{OAc})_{2}$ /TPPTS in an ethylmethylimidazolium tetrafluoroborate $[\mathrm{emim}]\left[\mathrm{BF}_{4}\right] / \mathrm{H}_{2} \mathrm{O}$ system (Scheme 33$) .{ }^{146}$ The catalyst from ionic liquid/water medium can be recycled eight times without loss of catalytic activity.

\subsection{Sonogashira coupling}

Sonogashira coupling reaction is recognized as a powerful and reliable synthetic method for the formation of substituted or nonsubstituted acetylenes (Scheme 34). ${ }^{147-150}$ The coupling of terminal alkynes with aryl or vinyl halides/ triflates is performed in presence of palladium catalyst, and $\mathrm{CuI}$ as cocatalyst, and amine is used as a base. Generally, the reaction requires anhydrous and anaerobic conditions, but newer procedures have been developed where these restrictions are not important.

Since, ILs have been utilized as solvents in many transition metal catalyzed $\mathrm{C}-\mathrm{C}$ bond formation reactions, the same was also tried for Sonogashira coupling reactions and found to be equally important. ${ }^{151-154}\left[(\right.$ Bisimidazole $) \mathrm{Pd}\left(\mathrm{CH}_{3}\right)$

Scheme 31 .

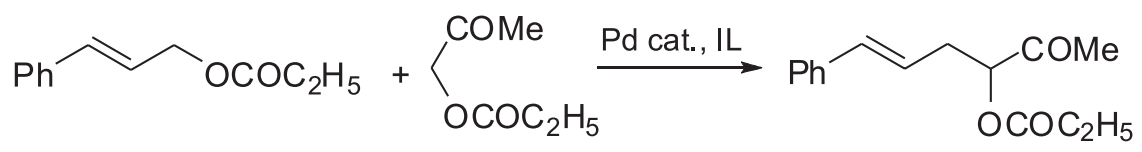

Scheme 32 .

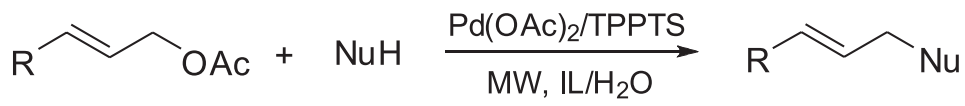

Scheme 33.

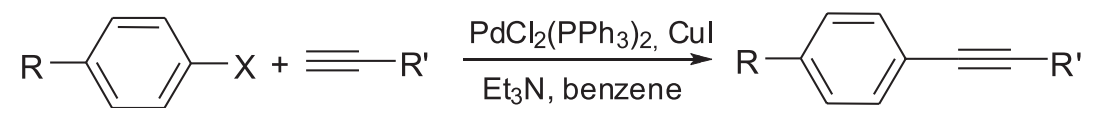

Scheme 34. 
$\mathrm{Cl}$ c catalyzes this reaction efficiently without copper salts or bulky phosphine ligands in IL, and catalyst was recycled many times without any loss of catalytic activity. ${ }^{152}$ Crosscoupling and carbonylative coupling of terminal alkynes with aryl iodides catalyzed by $\mathrm{PdCl}_{2}\left(\mathrm{P}(\mathrm{OPh})_{3}\right)_{2}$ in the presence of $\mathrm{Et}_{3} \mathrm{~N}$ in toluene results in the formation of the product in good yield. Same reaction was also performed ${ }^{153}$ in IL and it was observed that reaction takes less time. In ILs $[\mathrm{bmim}]\left[\mathrm{PF}_{6}\right]$ or $[$ mokt $]\left[\mathrm{PF}_{6}\right]$ (mokt = 1-methyl-3-octyl imidazolium cation), catalyst was recycled and used in four consecutive catalytic cycles without loss of catalytic activity. In the absence of aryl iodide, the same catalytic system catalyzed head-to-tail dimerization of phenylacetylene to the 1,3-diphenylenyne, trans $-\mathrm{PhC} \equiv \mathrm{C}-\mathrm{C}(\mathrm{Ph})=\mathrm{CH}_{2}$, with a yield of $85 \% .{ }^{153}$ Symmetrical and unsymmetrical tribenzohexadehydro[12] annulene and [12]annulenes have also been synthesized via cyclotrimerization under Sonogashira conditions in [bmim] $\left[\mathrm{BF}_{4}\right]$ (Scheme 35). Homocoupling was minimized under this reaction conditions. ${ }^{155}$

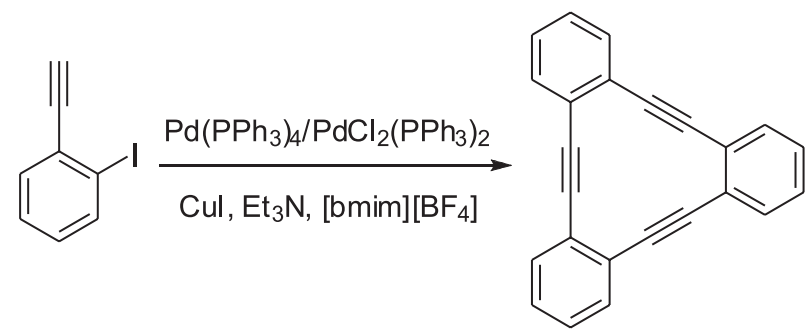

Scheme 35.

Sonogashira coupling reaction of aryl iodides with terminal acetylenes (aromatic or aliphatic) proceeds efficiently in IL, [bmim] $\left[\mathrm{PF}_{6}\right]$, using $\mathrm{PdCl}_{2}\left(\mathrm{PPh}_{3}\right)_{2}$ as the catalyst (Scheme 36). This reaction works well in the absence of a copper salt. The recycled catalyst was used without the loss of catalytic activity. Sonogashira coupling reaction using a microflow system has also been studied. ${ }^{154}$

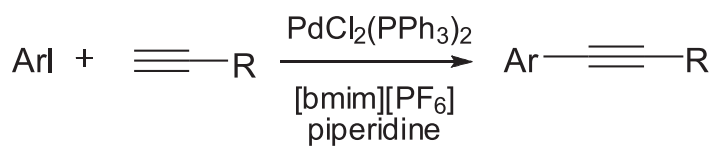

Scheme 36.
Carbonylative Sonogashira coupling reaction at low-pressure microflow system has been developed for palladium-catalyzed multi step carbonylation reactions in an ionic liquid (Scheme 37). Better selectivity and higher yields in carbonylative Sonogashira coupling and amidation reactions of aryl iodides has been reported in microflow system in comparison to the conventional batch system. ${ }^{156}$

Sonogashira coupling reaction has also been successfully carried out in the novel array reactor using palladiumcatalyst in ionic liquid in a parallel fashion. The array reactor as the reaction device and ionic liquids as the reaction media allowed synthesizing variety of compounds. Recycling of catalysts and ionic liquids, contributes not only to reaction economics and saving energy but also to environmental protection. ${ }^{157}$

A comparative study for solvent IL and PEG (polyethylenglycol) was done for both Sonogashira and Suzuki coupling reactions for developing a homogeneous and reusable palladium catalyst system. ${ }^{158}$ A carbapalladacycle complex (Figure 1) developed from 4-hydroxyacetophenone oxime and palladium salt was used as catalyst. It was found that PEG gave better results than ILs. This was due to the better stability of the complex in PEG than the ILs tested. ${ }^{158}$<smiles>COC1(C(F)(F)F)C(C)=[N+](O)c2cc(O)ccc21</smiles>

Figure 1.

\subsection{Carbonylation}

Carbonyl compounds have been the backbone of organic chemistry, and these compounds such as carboxylic acids, esters, amides, aldehydes and ketones have been effectively synthesized by Palladium-catalyzed carbonylation of aryl halides. Most of these reactions were also carried out in environmental friendly solvent ILs. Palladium-catalyzed alkoxycarbonylation of aryl halides was carried out in $[\mathrm{bmim}]\left[\mathrm{BF}_{4}\right]$ and $[\mathrm{bmim}]\left[\mathrm{PF}_{6}\right]$ with enhanced reactivity

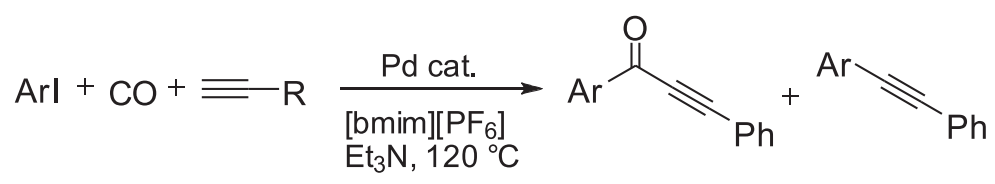


in the reusable ionic liquids (Scheme 38). ${ }^{159,160}$ The carbonylation of iodobenzene catalyzed by water-soluble palladium complexes and the role exerted by halogen free IL has been investigated. ${ }^{160}$ The author used sulphonated phosphine [TPPTS: $\mathrm{P}\left(m-\mathrm{C}_{6} \mathrm{H}_{4} \mathrm{SO}_{3} \mathrm{Na}\right)_{3}$, TPPDS: $\left(\mathrm{C}_{6} \mathrm{H}_{5}\right)$ $\left.\mathrm{P}\left(m-\mathrm{C}_{6} \mathrm{H}_{4} \mathrm{SO}_{3} \mathrm{Na}\right)_{2}\right]$, TPPMS: $\left.\left(\mathrm{C}_{6} \mathrm{H}_{5}\right)_{2} \mathrm{P}\left(m-\mathrm{C}_{6} \mathrm{H}_{4} \mathrm{SO}_{3} \mathrm{Na}\right)\right]$

and bidentate ligand BISBIS (BISBIS: sodium salt of sulphonated 2,2'-bis(diphenylphosphinomethyl)-1,1'biphenyl) for the carbonylation of iodobenzene (perhaps to avoid lixiviation) and the IL (1- $n$-butyl-3-methylimidazolium $p$-toluenesulphonate, ([bmim $\left.]\left[p-\mathrm{CH}_{3} \mathrm{C}_{6} \mathrm{H}_{4} \mathrm{SO}_{3}\right]\right)$ used as the reaction media has some definitive advantages over the halogen-containing analogue $\left[\mathrm{bmim} \mathrm{BF}_{4}\right.$, [bmim] $\mathrm{PF}_{6}$ and conventional organic solvents. The combination of palladium-TPPTS complex and [bmim] $\left[p-\mathrm{CH}_{3} \mathrm{C}_{6} \mathrm{H}_{4} \mathrm{SO}_{3}\right]$ exhibits excellent catalytic activity and selectivity, and simplifies the separation of the products from catalyst. ${ }^{160}$ The catalyst can be easily separated from the organic products and reused for 10 times without the significant decrease of activity and selectivity.

The biphasic alkoxycarbonylation of styrene catalyzed by palladium compounds in a [bmim] $\left[\mathrm{BF}_{4}\right]$-cyclohexane system was reported. ${ }^{161}$ The $\mathrm{PdCl}_{2}(\mathrm{PhCN})_{2}$ in combination with (C)-neomenthyldiphenylphosphine (NMDPP) and $p$-toluenesulphonic acid $(\mathrm{TsOH})$ dissolved in [bmim] $\left[\mathrm{BF}_{4}\right]$ was found to be the best catalyst precursor. The branched ester gave high regioselectivities (99.5\%). The intramolecular alkoxycarbonylation of alkynols was successfully performed using $\mathrm{Pd}(\mathrm{II}) / \mathrm{PyPh}_{2} \mathrm{P}$ complexes immobilized in $[\mathrm{bmim}]\left[\mathrm{BF}_{4}\right]$ or $[\mathrm{bmim}]\left[\mathrm{PF}_{6}\right]$ to afford selectively exo-methylene five- and six-membered lactones in high yields. ${ }^{162}$

Aminocarbonylation of alkynes with amines in presence of Palladium-catalyst in [bmim] $\left[\mathrm{Tf}_{2} \mathrm{~N}\right]$ based ionic liquid affords regiospecifically $\alpha$-methylene amides in good yields, without any acid additive (Scheme 39). ${ }^{163}$ The ionic liquid gave improved yields and regioselectivity in comparison to the molecular solvent. The catalyst system can be recycled and reused five times without significant loss of catalytic activity.

The ionic liquids such as $[\mathrm{bmim}]\left[\mathrm{PF}_{6}\right]$ or $[\mathrm{bmim}]\left[\mathrm{Tf}_{2} \mathrm{~N}\right]$, have been successfully used for the cyclocarbonylation of 2-allylphenols and anilines, 2-vinylphenols and 2 -aminostyrenes in presence of Palladium catalyst. ${ }^{164}$ The reaction proceeds efficiently to afford high yields with excellent selectivity of lactones or lactams. No side products were found in this reaction. The catalytic system and ligand can be recycled.

$\alpha, \beta$-Acetylenic ketones have been synthesized by threecomponent carbonylative coupling reaction of aryl iodides with terminal alkynes catalyzed by $\mathrm{PdCl}_{2}\left(\mathrm{PPh}_{3}\right)_{2}$ using ionic liquid [bmim] $\left[\mathrm{PF}_{6}\right]$, as the reaction medium. The lowviscosity ionic liquid [bmim] $\left[\mathrm{Tf}_{2} \mathrm{~N}\right]$, was not suitable for this reaction, since the background Sonogashira coupling reaction, a competing reaction, also proceeded. ${ }^{165}$ The Palladium-carbene catalyst $\mathbf{2}$ have also been successfully used for the carbonylation of aryl halides in IL. ${ }^{166}$ The combination of catalyst 2 and IL TBAB gave better result.

\subsection{Polymerization}

The cationic metal complexes with weakly coordinated anions usually catalyze copolymerization of alkenes. ${ }^{167}$ Polar non-coordinating ILs are attractive solvents for these reactions. This is due to their ability to stabilize the solvent-separated ion pairs that are necessary for a high activity. Chloroaluminate ILs have been applied to the cationic metal-catalyzed oligomerization and polymerization of alkenes. ${ }^{168,169}$ The air- and moisturestable IL such as $\left[\mathrm{C}_{4} \mathrm{mim}\right]\left[\mathrm{PF}_{6}\right]$ was used for ethylene oligomerization and ethylene-linked polymerization. ${ }^{170,171}$ ILs are also found to be suitable solvents for the palladiumcatalyzed alternating copolymerization of styrene and

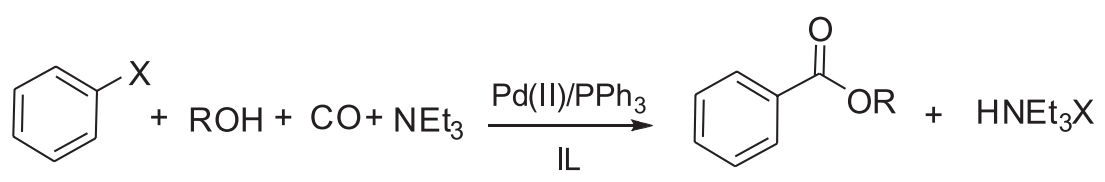

Scheme 38.

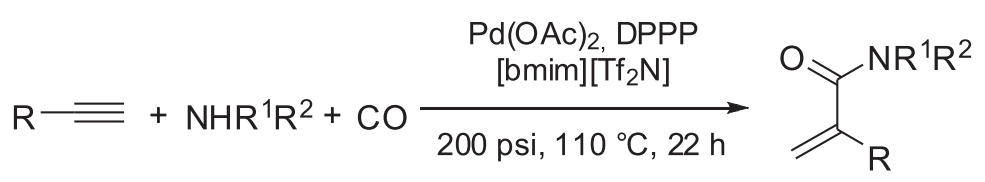

Scheme 39. 


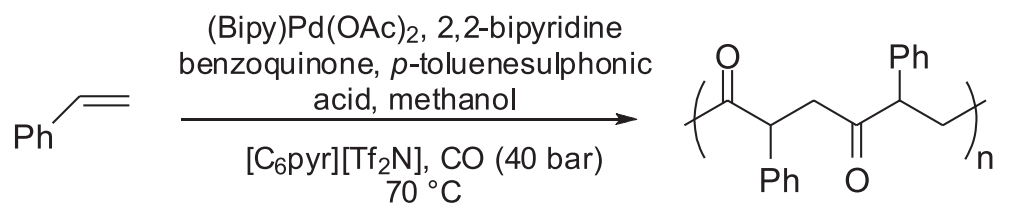

Scheme 40.

CO (Scheme 40). ${ }^{172}$ Polyketones was synthesized by the alternating copolymerization of styrene and CO using $\left[\mathrm{Pd}(\text { bipy })_{2}\right]\left[\mathrm{PF}_{6}\right]_{2}{ }^{173}$ in an ionic liquid media. The reaction was tried in various ionic liquids giving emphasis on the reusability of ionic liquid-catalyst system. ${ }^{174}$

The utility of a catalytic system consisting of $\mathrm{LPd}(\mathrm{OAc})_{2}(\mathrm{~L}=2,2$-bipyridine and 1,10-phenanthroline) excess ligand, benzoquinone and $p$-toluenesulphonic acid was also tested in IL. ${ }^{175}$ The pyridinium-based ionic liquids gave the best results, while lower yields were obtained in an imidazolium-based IL. No copolymer formation was observed in the phosphonium ILs. The halide-free IL solvents are critical to achieve a high activity and molecular weight because halides coordinate strongly to the vacant coordination site, inhibiting the catalyst activity. Lower yields were obtained during recycling the ionic liquid catalyst. This is most likely due to $\mathrm{Pd}$ precipitation during the polymerization reaction. In addition, extraction of the IL catalyst solution resulted in some mechanical loss. Despite these difficulties, $\left[\mathrm{C}_{6}\right.$ pyr $]\left[\mathrm{Tf}_{2} \mathrm{~N}\right] \mathrm{IL}$ has been found most effective solvent for the $\mathrm{Pd}$-catalyzed copolymerization of styrene and $\mathrm{CO} .{ }^{176} \mathrm{~A}$ higher molecular weight of polymer and improved catalyst stability were observed in $\left[\mathrm{C}_{6}\right.$ pyr $]\left[\mathrm{Tf}_{2} \mathrm{~N}\right]$ as compared to methanol. Methanol acted as a chain-transfer agent and a reductant for the $\mathrm{Pd}(\mathrm{II})$ catalyst to inactive $\mathrm{Pd}(0)$ clusters. By replacing methanol with $\left[\mathrm{C}_{6} \mathrm{pyr}\right]\left[\mathrm{Tf}_{2} \mathrm{~N}\right]$ chain transfer and catalyst decomposition appear to be inhibited. The increased activity could be due to improved catalyst stability and increased rate of propagation.

$\mathrm{Pd}$ in conjunction with IL has also been used for the stereoselective copolymerization reaction. The reaction of propene and carbon monoxide using Pd-complexes bearing chiral ligands $(2 S, 3 S)$-DIOP, $(R)$-BINAP and $(R)$-P-Phos in ILs medium such as $\left[\mathrm{C}_{4} \mathrm{mim}\right]\left[\mathrm{PF}_{6}\right] /\left[\mathrm{C}_{6} \mathrm{mim}\right]\left[\mathrm{PF}_{6}\right]$ lead to the formation of high molecular weight polyketones with almost complete regioregularity and moderate stereoregularity. ${ }^{177}$

\subsection{Hydrogenation}

Apart from the C-C bond formation, palladium catalyst in $\mathrm{IL}$ was also used to form $\mathrm{C}-\mathrm{H}$ bonds in hydrogenation reactions. The Pd-catalyzed hydrogenation of dienes to mono-hydrogenated olefins was effectively obtained in ILs. ${ }^{178}$ The hydrogenation of methyl isorbate by $\mathrm{Pd}(\mathrm{II})$ compounds dissolved in $[\mathrm{bmim}]\left[\mathrm{BF}_{4}\right]$ produces, mono hydrogenated diene as the main product and the product can be isolated quantitatively before further hydrogenation can take place (Scheme 41). This was one of the early examples of a homogeneous palladium catalyzed hydrogenation in IL. Palladium on carbon, entrapped in IL polymer gel $\left\{[\mathrm{Bmim}]\left[\mathrm{PF}_{6}\right] /\right.$ poly(vinylidene fluoride)hexafluopropylene copolymer \} was also used to hydrogenate propene. ${ }^{179}$ Palladium on carbon was also used as a catalyst for transfer hydrogenation of alkenes, alkynes, and nitrocompounds, using microwave irradiation, with formic acid as the hydrogen source in $[\mathrm{Bmim}]\left[\mathrm{PF}_{6}\right] .{ }^{180}$ The catalytic hydrogenation of citral was performed using palladium acetylacetonate $\left[\mathrm{Pd}(\mathrm{acac})_{2}\right]$ immobilized on a structurally active carbon cloth carrier in different ILs ([bmim] $\left[\mathrm{PF}_{6}\right]$, $\left.[\mathrm{bmim}]\left[\mathrm{BF}_{4}\right] \&[\mathrm{~A} 336]\left[\mathrm{PF}_{6}\right]\right) .{ }^{181}$ The novel IL [A336] $\left[\mathrm{PF}_{6}\right]$ was derived from a common phase transfer catalyst Aliquat 336. It was observed that the selectivity profiles of citral hydrogenation can be efficiently influenced not only by varying the transition metal species in line with classical catalysis and the experimental conditions (temperature, pressure), but also by the choice of the ionic liquid in which the transition metal species is dissolved. This concept shows prominent potential for industrial operations. The selective hydrogenation of 1,3-butadiene to 1-butene was obtained in $\mathrm{Pd}(0)$ nanoparticles embedded in IL. ${ }^{182} \mathrm{Pd}(0)$ nanoparticles with relatively small diameters and narrow size distributions was prepared by simple hydrogen reduction of $\mathrm{Pd}(\mathrm{acac})_{2}$ dispersed in ionic liquid. Selectivity up to $97 \%$ in butenes were observed in the hydrogenation of 1,3-butadiene by
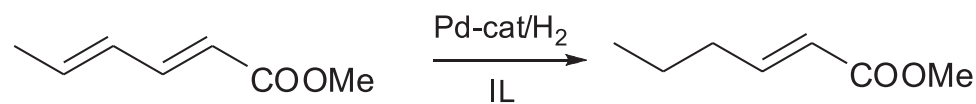

Scheme 41. 
$\mathrm{Pd}(0)$ nanoparticles embedded in $[\mathrm{bmim}]\left[\mathrm{BF}_{4}\right]$ at $40{ }^{\circ} \mathrm{C}$ temperature and $4 \mathrm{~atm}$ of hydrogen at constant pressure. ${ }^{182}$

\subsection{Miscellaneous reactions}

Silylstannanes are versatile organometallic reagents in organic synthesis. These compounds contain silicontin bond and are easily synthesized by generating a trialkyltin anion followed by a quench with trialkylsilyl chloride. ${ }^{183}$ The resulting silylstannanes can be added across unsaturated bonds via palladium catalyst to afford a bifunctional organic dianion equivalent containing both carbon-silicon and carbon-tin bonds (Scheme 42). ${ }^{184-188}$ These products can be selectively destannylated or desilylated, or silyl, stannyl groups can be substituted or the stannyl groups can participate in the Stille couplings. As the addition of silylstannanes across unsaturated systems uses expensive palladium catalysts, immobilization of the palladium catalyst in ILs that allows recycling of the catalyst without loss of activity was seen as a potentially useful application of the ILs in the organic synthesis. ${ }^{189}$ Silylstannanes can be regioselectively added across terminal alkynes in a quantitative fashion in the presence of a palladium $(0)$ catalyst immobilized in the $[\mathrm{bmim}]\left[\mathrm{PF}_{6}\right]$ which can be recycled without loss of activity.

Not surprisingly, palladium catalyzed C-C and C-heteroatom bond forming reactions can be performed in RTILs and in most of the cases the ionic liquid has a strong beneficial effect on the reaction rate and selectivity. For instance, allylic alkylations and aminations in IL have been reported (Scheme 43). ${ }^{190}$

Oxidation of alcohols to the corresponding aldehydes and ketones is one of the most important functional group transformations in organic synthesis. Of a number of methods that are employed, Seddon and co-workers demonstrated that benzyl alcohols could be oxidized selectively to benzaldehydes in dry ILs using $\mathrm{Pd}(\mathrm{OAc})_{2}$ as a catalyst and $\mathrm{O}_{2}$ as an oxidant. ${ }^{191}$ Wacker-type oxidation reactions were performed with water by $\mathrm{PdCl}_{2}$ immobilized in $[\mathrm{bmim}]\left[\mathrm{BF}_{4}\right]$ and $[\mathrm{bmim}]\left[\mathrm{PF}_{6}\right]$ using hydrogen peroxide as the oxidant. ${ }^{192}$

Recently Li et al. ${ }^{193}$ reported the synthesis of aryl and aryl vinyl nitriles using anhydrous $\mathrm{K}_{4}\left[\mathrm{Fe}(\mathrm{CN})_{6}\right]$ in ionic liquid under microwave irradiation (Scheme 44). Various Pd catalysts in combination with ligands have been used, and $\mathrm{PdCl}_{2} / \mathrm{DMEDA}$ system in IL has been found to be the best medium for this reaction. The cyanides used for this study

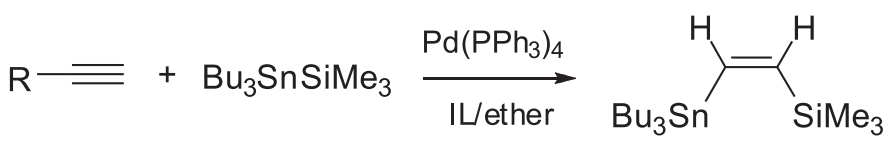

Scheme 42.<smiles>COC(=O)C(C#N)C(/C=C/c1ccccc1)C1CCCCC1(OC(C)=O)C(C#N)c1ccccc1</smiles>

Scheme 43.

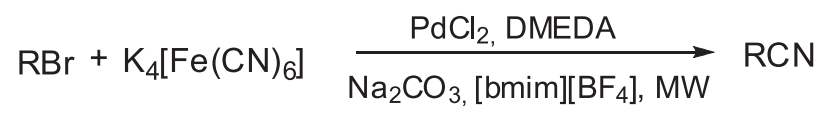


has been non-toxic and inexpensive. The reaction time was reduced greatly under microwave heating and the catalyst system can be recycled and reused several times.

A facile method for the synthesis of 3,4-disubstituted hydrazinocyclopentene derivatives has been developed by the palladium( 0 )/Lewis acid mediated ring-opening of azabicyclic olefins with organostannanes (Scheme 45). ${ }^{194}$ Use of catalytic amount of Lewis acid increase the rate of the reaction, and it was observed that rate of the reaction was very slow in toluene, while in ionic liquid [Bmim] $\left[\mathrm{PF}_{6}\right]$ the reaction rate was enhanced. The reaction in ionic liquid without Lewis acid leads to the ring-opened product, hydrazino cyclopentene.

A general method for the synthesis of 3-substituted indole derivatives via $\mathrm{PdCl}_{2}\left[\mathrm{CH}_{3} \mathrm{CN}\right]_{2}$-catalyzed Michael reaction of indoles with $\alpha, \beta$-unsaturated ketones in [bmim] $\left[\mathrm{BF}_{4}\right]$ has been developed (Scheme 46). ${ }^{195}$ High selectivity, mild reaction conditions, and good yield of the product are the main advantage of this method. The catalyst system
$\mathrm{PdCl}_{2}\left(\mathrm{CH}_{3} \mathrm{CN}\right)_{2} /[\mathrm{bmim}]\left[\mathrm{BF}_{4}\right]$ can be recovered and reused without noticeable loss of the catalytic activity.

Palladium salts and complexes dissolved in imidazolium ionic liquids can also promote the cycloisomerization of 1,6-heptadienes. ${ }^{196}$ The order of reactivity follows the hardness of $\mathrm{Pd}$ atom and "naked" $\mathrm{Pd}^{2+}$ generated from $\mathrm{PdCl}_{2}+\mathrm{AgPF}_{6}$ gives the highest turnover frequencies. Functionalized symmetrical biaryls have been synthesized in good yields via TDAE/Pd-promoted homocoupling reaction of substituted iodoarenes using the ionic liquid, [bmim] $\left[\mathrm{PF}_{6}\right]$ (Scheme 47). ${ }^{197}$ The catalytic system could be recycled and reused four times without any loss in the catalytic activity.

The C-P cross-coupling reactions between phosphineborane complexes and aryl iodides have also been reported in imidazolium based ILs (Scheme 48). ${ }^{198}$ The best results were obtained in $[\mathrm{bmim}]\left[\mathrm{PF}_{6}\right]$. The easy separation of the product and the catalyst without any aqueous work-up has been the main advantage of this reaction. The palladium catalyst $[\mathrm{dppp}]\left[\mathrm{PdCl}_{2}\right]$ can be recycled three times.

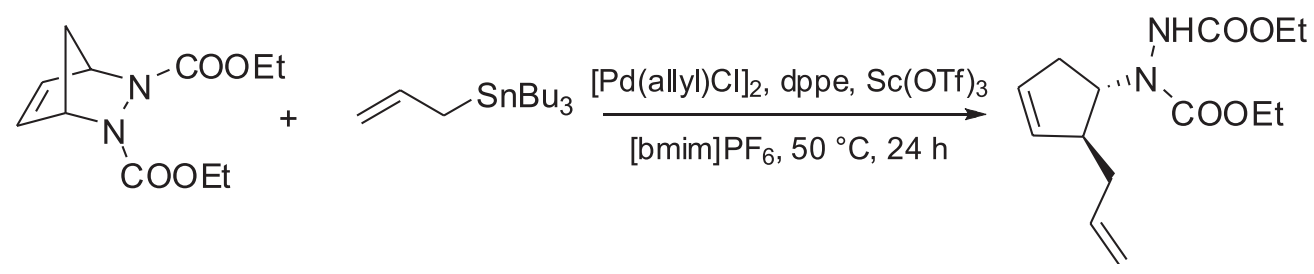

Scheme 45.

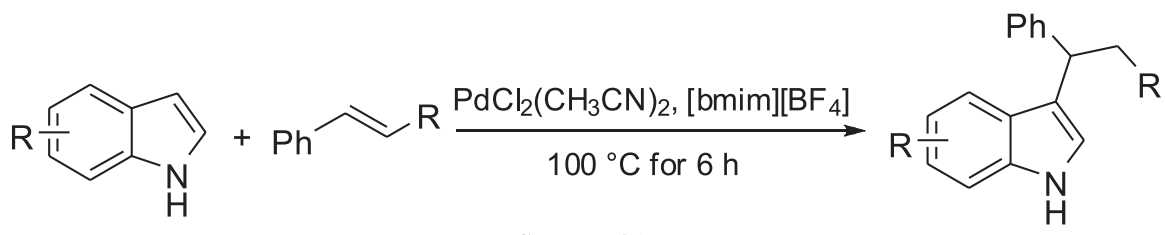

Scheme 46.

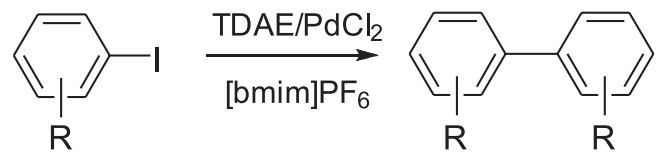

Scheme 47.<smiles>Fc1cccc(I)c1</smiles><smiles>[R][PH]([B])([B])c1ccccc1</smiles>

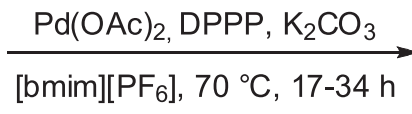<smiles>[R]c1cccc([PH]([R])([B])c2ccccc2)c1</smiles>

Scheme 48. 
The linear dimerization of 1,3-butadiene was performed with palladium complexes immobilized in ILs. ${ }^{199}$ The, $\mathrm{Pd}(\mathrm{II})$ salt (chloride or acetate)/ $\mathrm{PPh}_{3}$ catalyst precursors dissolved in (bmim) $\mathrm{F}_{4}$ or (bmim) $\mathrm{PF}_{6}$ catalyzed the linear dimerization of 1,3-butadiene to 1,3,6-octatriene. The catalyst precursor derived from $\mathrm{PdCl}_{2}$ with 2 equiv of $\mathrm{PPh}_{3}$ was used as the catalyst precursor, dissolved in (bmim) $\mathrm{BF}_{4} \mathrm{IL}$, octatriene was formed with $100 \%$ selectivity after $13 \%$ conversion. The TOF of $49 \mathrm{~h}^{-1}$ is significantly higher than in homogeneous conditions (THF, TOF $6 \mathrm{~h}^{-1}$ ) under the same reaction conditions. RTILs are also used as cosolvents in the Pd-catalyzed telomerization of butadiene with methanol leading to the formation of 1-methoxy2,7-octdiene and 3-methoxy-1,7-octdiene as the major product. ${ }^{200}$ The basic catalyst is $\mathrm{Pd}(\mathrm{II})$ acetate with either $\mathrm{PPh}_{3}$ or TPPMS, which was reacted with butadiene and methanol at $85{ }^{\circ} \mathrm{C}$. A biphasic catalytic system was also developed using Pd(II) acetate, TPPMS, heptane, and 1-butyl-2,3-dimethylimidazolium bis((trifluoromethyl) sulfonyl)imidate, [bdmim] $\left[\mathrm{TF}_{2} \mathrm{~N}\right]$. In this case, after the telomerization reaction, the methoxyoctadiene products were recovered by simple decantation and the IL phase reintroduced to the reactor, allowing the catalyst to be reused. In this way, the catalyst was recycled four times $\left(\mathrm{TON}=10^{3}\right)$ with little loss of activity. ${ }^{183}$

\section{Summary and Future Prospects}

The studies have shown that classical transition-metal catalyzed reactions can be performed in ionic liquids. Due to better immolizing power IL's have many advantages over conventional solvents. A combination of subtle (i.e. changing cation substitution patterns) and gross (anion type) modifications to the ionic liquid solvent can permit very precise tuning of reactions. Ionic liquids have been used as effective solvents and catalysts for clean chemical reactions as replacements for volatile organic and dipolar aprotic solvents (i.e. DMF, DMSO) and solid acid catalysts in reactions ranging from the laboratory to industrial scale. They provide a medium for clean reactions with minimal waste and efficient product extraction, an area that is currently being investigated.

The future directions for catalytic reactions in ionic liquid solvents clearly rely on screening existing catalysts and a greater depth of understanding of the features influencing the specific solvent properties of the different types of ionic liquids. It is anticipated that screening of various catalytic systems via combinatorial approach will have a significant role to play. The separation, post-reaction, of ionic liquids and catalysts from reaction products is an unresolved challenge in the application of ionic liquids to organometallic catalysis.

\section{Acknowledgments}

DSR thanks UGC, New Delhi and RS thanks Department of Science and Technology (DST), New Delhi, India for the financial support, under Fast Track Young Scientist Scheme.

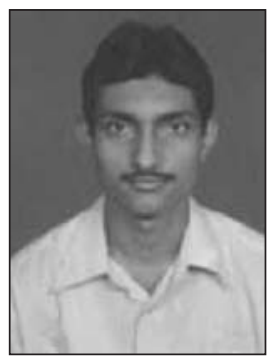

Dr. Ram Singh was born in a village Chandauli of the Sitamarhi district, Bihar, India in 1976. He studied chemistry at Ramjas College (University of Delhi), Delhi, India and received his $B S c$ and MSc degrees in 1996 and 1998, respectively. After completing his MSc he joined Professor S. M.

$S$. Chauhan's group and worked on heterocyclic and natural product chemistry. University Grant Commission, New Delhi, India, awarded him research fellowship. He received his $P h D$ degree in organic chemistry from Department of Chemistry, University of Delhi, India in February 2003. He worked as Postdoctoral Fellow in the Department of Biotechnology (DBT), Delhi, India sponsored multi-institutional, and multidisciplinary research project entitled "Prospecting for Natural Dyes from Bioresources" coordinated by the Centre for Environmental Management of Degraded Ecosystems (CEMDE), University of Delhi. Currently he is working as Fast Track Young Scientist awarded by Department of Science and Technology (DST) Delhi, India in Department of Chemistry, University of Delhi, Delhi, India. His research interest lies in medicinal chemistry, design and development of newer synthetic methodologies, molecular recognition and natural product chemistry.

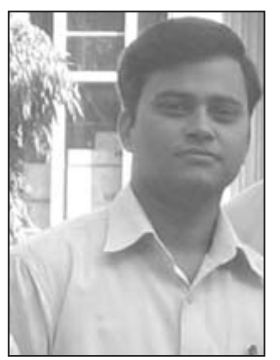

Mukul Sharma was born in 1982 in Firozabad, Uttar Pradesh, India. He graduated from CLC College, Firozabad and received his MSc degree from $\operatorname{Dr}$ B.R. Ambedkar University, Agra, India. He is currently carrying out his PhD under the supervision of Dr. Diwan S. Rawat, Reader, at Department of Chemistry, University of Delhi, India. He has been awarded research fellowship by Council of Scientific and Industial Research (CSIR), New Delhi, India. His research interest deals with the synthesis of biologically active compounds. 


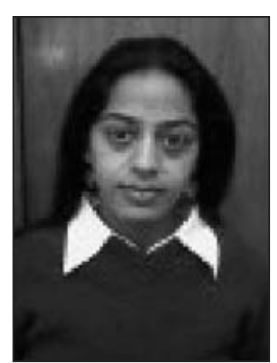

Ms Ritu Mamgain was born in 1979 in Srinagar, Uttaranchal, India. She graduated from Mahadevi Kanya Pathsala College, Dehradun, and received her Master of Science degree from Sri Guru Ram Rai College, Dehradun, H.N.B. Garhwal University, Uttaranchal. She is currently carrying out her PhD under the supervision of Dr. Diwan S. Rawat, Reader, at Department of Chemistry, University of Delhi, India. Her research deals with the development of ionic liquids as novel media in organic reactions. She is involved in the synthesis of antimalarial compounds.

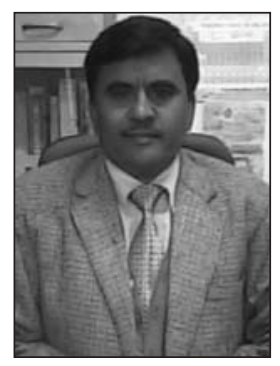

Dr. Diwan S. Rawat was born in Raikholi village of the Bageshwar district, Uttrakhand, India in 1970. He obtained his master's degree from Kumaun University Nainital, Uttrakhand and was honored with the merit certificate of Kumaun University, Nainital for getting first position in the university in MSc examination. In April 1994 he moved to Central Drug Research Institute, Lucknow, UP, India, and obtained his PhD degree in 1998 under the joint supervision of Dr. D. S. Bhakuni and Prof. C. S. Mathela. Dr. Rawat worked as an $R \& D$ Executive, Panchsheel Organic Limited, Indore for a year and in 1998 he joined Lupin Laboratories Ltd Mandideep as a scientist. In November 1999 he joined Prof. J. M. Zaleski's research group at Indiana University, Bloomington, USA. After two years stay at Indiana University, he moved to Department of Medicinal Chemistry and Molecular Pharmacology, Purdue University, USA, where he worked with Prof. R. A. Gibbs. He was an Assistant Professor of Medicinal Chemistry at National Institute of Pharmaceutical Education and Research (NIPER), Mohali, before taking over his new position as a Reader at Department of Chemistry, University of Delhi. His research interest includes design and synthesis of genotoxic and non-genotoxic anticancer agents, endoperoxide based antimalarials, process development of novel drugs and drug intermediates, development of new catalyst, heterocyclic and supramolecular chemistry.

\section{References}

1. Mandal, P. K.; Saha, S.; Karmakar, R.; Curr. Sci. 2006, 90, 301 .
2. Soares, V. C. D.; Alves, M. B.; Souza, E. R.; Pinto, I. O.; Rubim, J. C.; Andrade, C. K. Z.; Suarez, P. A. Z.; Int. J. Mol. Sci. 2007, 8, 392.

3. Frackowiak, E.; J. Braz. Chem. Soc. 2006, 17, 1074.

4. Souza, R. F. D.; Dupont, J.; Dullius, J. E. D. L.; J. Braz. Chem. Soc. 2006, 17, 48 .

5. Adya, A. K.; J. Ind. Chem. Soc. 2005, 82, 1197.

6. Harper, J. B.; Kobrak, M. N.; Mini-Reviews Org. Chem. 2006, 3,253 .

7. Leveque, J. M.; Cravotto, G.; Chimia 2006, 60, 313.

8. Ding, J.; Armstrong, D. W.; Chirality 2005, 17, 281.

9. Brennecke, J. F.; Maginn, E. J.; AIChE Journal 2001, 47, 2384.

10. Cull, S. G.; Holbrey, J. D.; Vargas-Mora, V.; Seddon, K. R.; Lye, G. J.; Biotechnol. Bioeng. 2000, 69, 227.

11. Dupont, J.; J. Braz. Chem. Soc. 2004, 15, 341.

12. Suarez, P. A. Z.; Consorti, C. S.; Souza, R. F. de; Dupont, J.; Gonçalves, R. S.; J. Braz. Chem. Soc. 2002, 13, 106.

13. Dupont, J.; Consorti, C. S.; Spencer, J.; J. Braz. Chem. Soc. 2000, 11, 337.

14. Ly ka, A.; Koloni ný, A.; Šimunek, P.; Machá ek, V.; Dyes Pigments 2007, 72, 208.

15. Singh, R.; Geetanjali; J. Braz. Chem. Soc. 2005, 16, 666.

16. Blanco, C. G.; Banciella, D. C.; Azpíroz. M. D. G.; J. Mol. Catal. A: Chem. 2006, 253, 203.

17. Naik, P. U.; Nara, S. J.; Harjani, J. R.; Salunkhe, M. M.; J. Mol. Catal. B: Enzym. 2007, 44, 93.

18. Canal, J. P.; Ramnial, T.; Dickie, D. A.; Clyburne, J. A. C.; Chem. Commun. 2006, 1809.

19. MacFarlane, D. R.; Pringle, J. M.; Johansson, K. M.; Forsyth, S. A.; Forsyth, M.; Chem. Commun. 2006, 1905.

20. Cocalia, V. A.; Gutowski, K. E.; Rogers, R. D.; Coord. Chem. Rev. 2006, 250, 755.

21. Jorapur, Y. R.; Dae, Y. C.; Bull. Korean Chem. Soc. 2006, 27, 345.

22. Calo, V.; Nacci, A.; Monopoli, A.; J. Organometal. Chem. 2005, $690,5458$.

23. Jain, N.; Kumar, A.; Chauhan. S.; Chauhan, S. M. S.; Tetrahedron 2005, 61, 1015.

24. Fuchigami, T.; Tajima, T.; J. Fluorine Chem. 2005, 126, 181.

25. Zhao, D.; Wu, M.; Kou, Y.; Min, E.; Catalysis Today 2002, 2654, 157

26. Earle, M. J.; Esperança, J. M. S. S.; Gilea, M. A.; Lopes, J. N. C.; Rebelo, L. P. N.; Magee, J. W.; Seddon, K. R.; Widegren, J. A.; Nature 2006, 439, 831.

27. Li, X.; Zhao, D.; Fei, Z.; Wang, L.; Science in China 2006, 35B, 385.

28. Souza, R. L. de; Tubino, M.; J. Braz. Chem. Soc. 2005, 16, 1068.

29. Liane M. R.; Dupont, J.; Machado, G., Fichtner, P. F. P.; Radtke, C. B.; Israel J. R.; Teixeira, S. R.; J. Braz. Chem. Soc. 2004, 15, 904. 
30. Safavi, A.; Maleki, N.; Tajabadi, F.; Farjami, E.; Electrochem. Commun. 2007, 9, 1963.

31. Wasserscheid, P.; Keim, W.; Angew. Chem. Int. Ed. 2000, 39, 3773.

32. Wasserscheid, P.; Welton, T.; Ionic Liquids in Synthesis, $1^{\text {st }}$ ed., Wiley-VCH, 2002.

33. Adams, D. J.; Dyson, P. J.; Taverner, S. J.; Chemistry in Alternative Reaction Media, $1^{\text {st }}$ ed., Wiley-VCH, 2003.

34. Walden, P.; Bull. Acad. Sci. St Petersburg 1914, 405.

35. Yokozeki, A.; Shiflett, M. B.; Appl. Energy 2007, 84, 351.

36. Earle, M. J.; Seddon, K. R.; Pure Appl. Chem. 2000, 72, 1391.

37. Welton, T.; Chem. Rev. 1999, 99, 2071.

38. Holbrey, J.; Seddon, K. R.; Clean Prod. Proc. 1999, 1, 223.

39. Seddon, K. R.; J. Chem. Tech. Biotech. 1997, 68, 351.

40. Handbook of Organopalladium Chemistry for Organic Synthesis; Negishi, E., ed.; Wiley-Interscience: New York, 2002, vol. 1.

41. Sgalla, S.; Fabrizi, G.; Cacchi, S.; Macone, A.; Bonamore, A.; J. Mol. Cat. B: Enzym. 2007, 44, 144.

42. Forsyth, S. A.; Pringle, J. M.; MacFarlane, D. R.; Aust. J. Chem. 2004, 57, 113.

43. Santos, L. S.; Neto, B. A. D.; Consorti, C. S.; Pavam, C. H.; Almeida, W. P.; Coelho, F.; Dupont, J.; Eberlin, M. N.; J. Phys. Org. Chem. 2006, 19, 731.

44. Carlin, R. T.; Osteryoung, R. A.; J. Mol. Catal. 1990, 63, 125.

45. Waffenschmidt, H.; Wasserscheid, P.; J. Mol. Catal. A: Chem. 2000, 164, 61

46. Chauvin, Y.; Gilbert, B.; Guibard, I.; J. Chem. Soc. Chem. Commun. 1990, 1715.

47. Dyson, P. J.; Trans. Metal Chem. 2002, 27, 353.

48. Dyson, P. J.; Ellis, D. J.; Parker, D. G.; Welton, T.; J. Mol. Catal. A: Chem. 1999, 150, 71.

49. Dyson, P. J.; Russell, K.; Welton, T.; Inorg. Chem. Commun. 2001, 4, 571.

50. Welton, T.; Smith, P. J.; Adv. Organometal. Chem. 2004, 51, 251.

51. Calo, V.; Nacci, A.; Monopoli, A.; Eur. J. Org. Chem. 2006, 3791.

52. Chiappe, C.; Imperato, G.; Napolitano, E.; Pieraccini, D.; Green Chem. 2004, 6, 33.

53. Xiao, J. C.; Shreeve, J. M.; J. Org. Chem. 2005, 70, 3072.

54. Thathagar, M. B.; Kooyman, P. J.; Boerleider, R.; Jansen, E.; Eleevier, C. J.; Rothenberg, G.; Adv. Synth. Catal. 2005, 347, 1965.

55. Mo, J.; Xu, L.; Xiao, J.; J. Am. Chem. Soc. 2005, 127, 751.

56. Bohm, V. P. W.; Herrmann, W. A.; Chem. Eur. J. 2000, 6, 1017.

57. Beletskaya, I. P.; Cheprakov, A. V.; Chem. Rev. 2000, 100, 3009 .
58. Heck, R. F.; J. Am. Chem. Soc. 1968, 90, 5518

59. Heck, R. F.; Org. React. 1982, 27, 345.

60. de Meijere, A.; Meyer Jr., F. E.; Angew. Chem. Int. Ed. 1994, 33,2379

61. Heck, R. F.; Nolley Jr., J. P.; J. Org. Chem. 1972, 37, 2320.

62. Dominguez, B.; Iglesia, B.; de Lera, A. R.; J. Org. Chem. 1998, 63,4135 .

63. Lipshutz, B. H.; Ullman, B.; Lindsley, C.; Pecchi, S.; Buzard, D. J.; Dickson, D.; J. Org. Chem. 1998, 63, 6092.

64. Beccaria, L.; Deagostino, A.; Prandi, C.; Zavattaro, C.; Venturello, P.; Synlett 2006, 2989.

65. Pinto, A.; Jia, Y.; Neuville, L.; Zhu, J.; Chem. Eur. J. 2007, 13, 961.

66. Bader, R. R.; Baumeister, P.; Blaser, H. U.; Chimia 1996, 50, 99.

67. Stambuli, J. P.; Stauffer, S. R.; Shaughnessy, K. H.; Hartwig, J. F.; J. Am. Chem. Soc. 2001, 123, 2677.

68. Lee, S.; Hartwig, J. F.; J. Org. Chem. 2001, 66, 3402.

69. Shaughnessy, K. H. ; Kim, P.; Hartwig, J. F.; J. Am. Chem. Soc. 1999, $121,2123$.

70. Grushin, V. V.; Alper, H.; Chem. Rev. 1994, 94, 1047.

71. Carpentier, J. F.; Petit, F.; Mortreux, A.; Dufaud, V.; Basset, J. M.; Thivolle-Cazat, J.; J. Mol. Catal. 1993, 81, 1.

72. Karymann, D. E.; Nouruzian, M.; Henze, H.; Synlett 1996, 1091.

73. Carmichael, A. J.; Earle, M. J.; Holbrey, J. D.; Mc Lormac, P. B.; Seddon, K. R.; Org. Lett. 1999, 1, 997.

74. Xu, L.; Chen, W.; Xiao, J.; Organometallics 2000, 19, 1123.

75. Bouquillion, S.; Ganchegui, B.; Estrine, B.; Henin, F.; Muzart, J.; J. Organomet. Chem. 2001, 634, 153.

76. Howarth, J.; Dallas, A.; Molecules 2000, 5, 851.

77. Mo, J.; Ruan, J.; Xu, L.; Hyder, Z.; Saidi, O.; Liu, S.; Pei, W.; Xiao, J.; J. Mol. Catal. A: Chem. 2007, 261, 267.

78. Liu, Y.; Li, M.; Lu, Y.; Gao, G. -H.; Yang, Q.; He, M. -Y.; Catal. Commun. 2006, 7, 985.

79. Deshmukh, R. R.; Rajagopal, R.; Srinivasan, K. V.; Chem. Commun. 2001, 1544.

80. Mason, T. J.; Chem. Soc. Rev. 1997, 26, 443.

81. Zou, G.; Wang, Z.; Zhu, J.; Zang, J.; He, Y.Y.; J. Mol. Catal. A: Chem. 2003, 206, 193.

82. Li, S.; Lin, Y.; Xie, H.; Zhang, S.; Xu, J.; Org. Lett., 2006, 8, 391 .

83. Mizoroki, T.; Mori, K.; Ozaki, A.; Bull. Chem. Soc. Jpn. 1971, 44,581 .

84. Metal-Catalyzed Cross-Coupling Reactions; Meijere, A.; Diederich, F., eds.; 2 ${ }^{\text {nd }}$ ed.; Wiley-VCH: Weinheim, 2004.

85. Hassan, J.; Sevignon, M.; Gozzi, C.; Schulz, E.; Lemair, M.; Chem. Rev. 2002, 102, 1359.

86. Blaser, H. U.; Spencer, A.; J. Organomet. Chem. 1982, 233, 267. 
87. Dubbaka, S. R.; Vogel, P.; Adv. Synth. Catal. 2004, 346, 1793.

88. Dubbaka, S. R.; Vogel, P.; Angew. Chem. Int. Ed. Engl. 2005, 44, 7674.

89. Dubbaka, S. R.; Zhao, D.; Fei, Z.; Volla, C. M. R.; Dyson, P. J.; Vogel, P.; Synlett 2006, 3155.

90. Hagiwara, H.; Sugawara, Y.; Isobe, K.; Hoshi, T.; Suzuki T.; Org. Lett. 2004, 6, 2325.

91. Hierso, J. C.; Picquet, M.; Cattey, H.; Meunier, P.; Synlett 2006, 3005 .

92. Forsyth, S. A.; Gunaratne, H. Q. N.; Hardacre, C.; McKeown, A.; Rooney, D. W.; Seddon, K. R.; J. Mol. Catal. A: Chem. 2005, 231, 61 .

93. Hierso, J. -C; Boudon, J.; Picquet, M.; Meunier, P.; European J. Org. Chem. 2007, 583.

94. Handy, S. T.; Synlett 2006, 3176.

95. Wang, R.; Twamley, B.; Shreeve, J. M.; J. Org. Chem. 2006, $71,426$.

96. Mo, J.; Liu, S.; Xiao, J.; Tetrahedron 2005, 61, 9902.

97. Pei, W.; Mo, J.; Xiao, J.; J. Organometallic Chem. 2005, 690, 3546.

98. Wang, L.; Zhang, Y.; Xie, C.; Wang, Y.; Synlett 2005, 1861.

99. Vallin, K. S. A.; Emilsson, P.; Larhed, M.; Hallberg, A.; J. Org. Chem. 2002, 67, 6243.

100. Xie, X.; Lu, J.; Chen, B.; Han, J.; She, X.; Pan, X.; Tetrahedron Lett. 2004, 45, 809.

101. Park, S. B.; Alper, H.; Org. Lett. 2003, 5, 3209.

102. Choudary, B. M.; Madhi, S.; Chowdari, N. S.; Kantam, M. L.; Sreedhar, B.; J. Am. Chem. Soc. 2002, 124, 14127.

103. Calo, V.; Nacci, A.; Monopoli, A.; Laera, S.; Cioffi, N.; J. Org. Chem. 2003, 68, 2929.

104. Mirzaei, Y. R.; Shreeve, J. M.; Synthesis 2003, 24.

105. Calo, V.; Delsole, R.; Nacci, A.; Schingro, E.; Scordari, F.; Eur. J. Org. Chem. 2000, 869.

106. Cassol, C. C.; Umpierre, A. P.; Machado, G.; Wolke, S. I.; Dupont, J.; J. Am. Chem. Soc. 2005, 127, 3298.

107. Cal, V.; Nacci, A.; Monopoli, A.; Ieva, E.; Cioffi, N.; Org. Lett. 2005, 7, 617 .

108. Cottineau, B.; Kessler, A.; O’Shea, D. F.; Org. Synth. 2006, 83, 45.

109. Miyaura, N.; Suzuki, A.; Chem. Commun. 1979, 866.

110. Suzuki, A.; Pure Appl. Chem. 1991, 63, 419.

111. Miyaura, N.; Suzuki, A.; Chem. Rev. 1995, 95, 2457; Suzuki, A.; J. Organomet. Chem. 1999, 576, 147.

112. Bai, L.; Wang, J. X.; Curr. Org. Chem. 2005, 9, 535.

113. Welton, T.; Smith, P. J.; Mathew, C. J.; $221^{\text {st }}$ American Chemical Society National Meeting, IEC-311, 2001.

114. Mathews, C. J.; Smith, P. J.; Welton, T.; White, A. J. P.; William, D. J.; Organometallics 2001, 20, 3848.

115. McLachlan, F.; Mathews, C. J.; Smith, P. J.; Welton, T.; Organometallics 2003, 22, 5350.
116. Mathews, C. J.; Smith, P. J.; Welton, T.; Chem. Commun. 2000, 1249.

117. Deshmukh, R. R.; Rajagopal, R.; Srinivasan, K.V.; Chem. Commun. 2001, 1544.

118. Rajagopal, R.; Jarikote, D. V.; Srinivasan, K. V.; Chem. Commun. 2002, 616.

119. McNulty, J.; Capretta, A.; Wilson, J.; Dyck, J.; Adjabeng, G.; Robertson, A.; Chem. Commun. 2002, 1986.

120. Wong, H.; Pink, C.J.; Ferreira, F. C.; Livingston, A. G.; Green Chem. 2006, 8, 373.

121. Ren, Y.; Yu, G. -A.; Guan, J.; Liu, S. H.; Appl. Organometal. Chem. 2007, 21, 1.

122. Cal, V.; Nacci, A.; Monopoli, A.; Montingelli F.; J. Org. Chem. 2005, 70, 6040 .

123. Yang, C. -H.; Tai, C. -C.; Huang, Y. -T.; Sun, I. -W.; Tetrahedron $\mathbf{2 0 0 5}, 61,4857$.

124. Zhao, D.; Fei, Z.; Geldbach, T. J.; Scopelliti, R.; Dyson, P. J.; J. Am. Chem. Soc. 2004, 126, 15876.

125. Mathews, C. J.; Smith, P. J.; Welton, T.; J. Mol. Catal. A: Chem. 2004, 214, 27.

126. Miao, W.; Chan, T. H.; Org. Lett. 2003, 5, 5003.

127. Revell, J. D.; Ganesan, A.; Org. Lett. 2002, 4, 3071.

128. Mee, S. P. H.; Lee, V.; Baldwin, J. E.; Angew. Chem. Int. Ed. Engl. 2004, 116, 1152; Kosugi, M.; Fugami, K.; J. Organomet. Chem. 2002, 653, 50.

129. Chiappe, C.; Pieraccini, D.; Zhao, D.; Fei, Z.; Dyson, P. J.; Adv. Synth. Catal. 2006, 348, 68.

130. Fei, Z.; Zhao, D.; Pieraccini, D.; Ang, W. H.; Geldbach, T. J.; Scopelliti, R.; Chiappe, C.; Dyson, P. J.; Organometallics 2007, $26,1588$.

131. Handy, S. T.; Zhang, X.; Org. Lett. 2001, 3, 233.

132. Chiappe, C.; Conte, V.; Pieraccini, D.; Eur. J. Org. Chem., 2001, 2831.

133. Chiappe, C.; Pieraccini, D.; Saullo, P.; J. Org. Chem. 2003, 68, 6710.

134. Liu, S.; Fukuyama, T.; Sato, M.; Ryu, I.; Synlett 2004, 1814.

135. Negishi, E.; Valente, L. F.; Kobayashi, M.; J. Am. Chem. Soc. 1980, 102, 3298.

136. Kobayashi, M.; Negishi, E.; J. Org. Chem. 1980, 45, 5223.

137. Negishi, E.; Acc. Chem. Res. 1982, 15, 340.

138. Sirieix, J.; Oberger, M.; Betzemeier, B.; Knochel, P.; Synlett 2000, 1613.

139. Chandrasekhar, S.; Jagadeshwar, V.; Saritha, B.; Narsihmulu, C.; J. Org. Chem. 2005, 70, 6506.

140. Tsuji, J. In Handbook of Organopalladium Chemistry for Organic Synthesis; Negishi, E., ed.; Wiley: New York, 2002, vol. 2, p. 1669.

141. Nelson, S. G.; Wang, K.; J. Am. Chem. Soc. 2006, 128, 4232.

142. Mancheno, O. G.; Priego, J.; Cabrera, S.; Arrayas, R. G.; Llamas, T.; Carretero, J. C.; J. Org. Chem. 2003, 68, 3679. 
143. Kinoshita, H.; Shinokubo, H.; Oshima, K.; Org. Lett. 2004, 6, 4085.

144. Chen, W.; Xu, L.; Chatterton, C.; Xiao, J.; Chem. Commun. 1999, 1247.

145. de Bellefon, C.; Pollet, E.; Grenouillet, P.; J. Mol. Catal. A: Chem. 1999, 145, 121.

146. Liao, M.; Duan, X.; Liang, Y.; Tetrahedron Lett. 2005, 46, 3469.

147. Gholap, A. R.; Venkatesan, K.; Pasricha, R.; Daniel, T.; Lahoti, R. J.;Srinivasan, K. V.; J. Org. Chem. 2005, 70, 4869.

148. Ginsburg, E. J.; Grubbs R. H. In Modern Acetylene Chemistry; Stang, P. J.; Diederich, F., eds.; VCH: Weinheim, 1995.

149. Sonogashira, K. In Handbook of Organopalladium Chemistry for Organic Synthesis; Negishi, E., ed.; John Wiley \& Sons: New York, 2002.

150. Chinchilla, R.; Najera, C.; Chem. Rev. 2007, 107, 874; Sonogashira, K. In Metal-Catalyzed Cross-Coupling Reactions; Diederich, F.; de Meijera, A., eds.; Wiley-VCH: Weinheim, 2004, vol. 1, p. 319.

151. Kmentova, I.; Gotov, B.; Gajda, V.; Toma, S.; Monatsh. Chemie 2003, 134, 545.

152. Park, S. B.; Alper, H.; Chem. Commun. 2004, 1306.

153. Sans, V.; Trzeciak, A. M.; Luis, S.; Ziółkowski, J. J.; Catalysis Lett. 2006, 109, 37.

154. Fukuyama, T.; Shinmen, M.; Nishitani, S.; Sato, M.; Ryu, I.; Org. Lett. 2002, 4, 1691.

155. Li, Y.; Zhang, J.; Wang, W.; Miao, Q.; She, X.; Pan, X.; J. Org. Chem. 2005, 70, 3285.

156. Rahman, Md. T.; Fukuyama, T.; Kamata, N.; Sato, M.; Ryu, I.; Chem. Commun. 2006, 2236.

157. Rahman, Md. T.; Fukuyama, T.; Ryu, I.; Suzuki, K.; Yonemura, K.; Hughes, P. F.; Nokihara, K.; Tetrahedron Lett. 2006, 47, 2703.

158. Corma, A.; Garcia, H.; Leyva, A.; Tetrahedron 2005, 61, 9848.

159. Mizushima, E.; Hayashi, T.; Tanaka, M.; Green Chem. 2001, 3,76 .

160. Lin, Q.; Yang, C.; Jiang, W.; Chen, H.; Li, X.; J. Mol. Catal. A: Chem. 2007, 264, 17.

161. Zim, D.; Dupont, J.; Souza, R. F.; Monteiro, A. L.; Tetrahedron Lett. 1998, 43, 8199.

162. Consorti, C. S.; Ebeling, G.; Dupont, J.; Tetrahedron Lett. 2002, 753.

163. Li, Y.; Alper, H.; Yu, Z.; Org. Lett. 2006, 8, 5199.

164. Ye, F. G.; Alper, H.; Adv. Synth. Catal. 2006, 348, 1855.

165. Fukuyama, T.; Yamaura, R.; Ryu, I.; Canad. J. Chem. 2005, 83, 711.

166. Calo`, V.; Giannoccaro, P.; Nacci, A.; Monopoli, A.; J. Organomet. Chem. 2002, 645, 152.

167. Drent, E.; Budzelaar, P. H. M.; Chem. Rev. 1996, 96, 663. 168. Murphy, V.; World Patent WO 0032658, 2000.
169. Carlin, R. T.; Wilkes, J. S.; J. Mol. Catal. 1990, 63, 125.

170. Wasserscheid, P.; Gordon, C. M.; Thlgers, C.; Mulddon, M. J.; Dunkin, J. R.; Chem. Commun. 2001, 1186.

171. Hlatky, G. G.; World Patent WO 0181436, 2001.

172. Klingshirn, M. A.; Broker, G. A.; Holbrey, J. D.; Shaughnessy, K. H.; Rogers, R. D.; Chem. Commun. 2002, 1394.

173. Milani, B.; Anzilutti, A.; Vicentini, L.; Sessanta, A.; Zangrando, S. E.; Geremia, S.; Mestronti, G.; Organometallics 1997, 16, 5064.

174. Hardacre, C.; Holbrey, J. D.; Katdare, S. P.; Seddon, K. R.; Green Chem. 2002, 4, 143.

175. Drent, L.; Eur. Pat. Appl. 1987, 229, 404.

176. Milani, B.; Corso, G.; Mestroni, G.; Carfagna, C.; Formica, M.; Seraglia, R.; Organometallics 2000, 19, 3435.

177. Wang, H. -J.; Wang, L. -L.; Lam, W. -S.; Yuc, W. -Y.; Chanb, A. S. C.; Tetrahedron: Asymmetry 2006, 17, 7.

178. Dupont, J.; Suarez, P. A. Z.; Umpierre, A. P.; de Souza, R. F.; J. Braz. Chem. Soc. 2000, 11, 293.

179. Carlin, R. T.; Fuller, J.; Chem. Commun. 1997, 1345.

180. Berthold, H.; Schotten, T.; Hönig, H.; Synthesis 2002, 1607.

181. Mikkola, J. -P.; Virtanen, P.; Karhu, H.; Salmia, T.; Murzin, D. Y.; Green Chem. 2006, 8, 197.

182. Umpierre, A. P.; Machado, G.; Fecher, G. H.; Morais, J.; Dupont, J.; Adv. Synth. Catal. 2005, 347, 1404.

183. Chenard B. L.; Van Zyl, C. M.; J. Org. Chem. 1986, 51, 3561.

184. Hemeon, I.; Singer, R. D.; Silyltin Reagents In Houben-Weyl Methods of Molecular Transformations Science of Synthesis; Fleming, I., ed.; Georg Thieme Verlag: New York, 2002, p. 205.

185. Mitchell, T. N.; Wickenkamp, R.; Amamria, A.; Dicke, R.; Schneider, U.; J. Org. Chem. 1987, 52, 4868.

186. Beletskaya, I.; Moberg, C.; Chem. Rev.,1999, 99, 3435.

187. Suginome, M.; Ito, Y.; Chem. Rev. 2000, 100, 3221.

188. Lautens, M.; Mancuso, J.; Synlett 2002, 3, 394.

189. Hemeon, I.; Singer, R. D.; Chem. Commun. 2002, 1884.

190. Chen, W.; Xu, L.; Chatterton, C.; Xiao, J.; Chem. Commun. 1999, 1247.

191. Seddon, K. R.; Stark, A.; Green Chem. 2002, 4, 119.

192. Varma, R. S.; Shale-Demessie, E.; Pillai, U. R.; Green Chem. 2002, 4, 170 .

193. Li, L. -H.; Pan, Z. -L.; Duan, X. -H.; Liang, Y. -M.; Synlett 2006, 2094

194. Radhakrishnan, K. V.; Sajisha, V. S.; Anas, S.; Syam Krishnan, K.; Synlett 2005, 2273.

195. Li, W. -J.; Lin, X. -F.; Wang, J.; Li, G. -L.; Wang, Y. -G.; Synlett 2005, 2003.

196. Corma, A.; García, H.; Leyva, A.; J. Organomet. Chem. 2005, $690,3529$.

197. Park, S. B.; Alper, H.; Tetrahedron 2004, 45, 5515. 
198. Vallette, H.; Pican, S.; Boudou, C.; Levillain, J.; Plaquevent, J. -C.; Gaumont, A. -C.; Tetrahedron Lett. 2006, 47, 5191.

199. Silva, S. M.; Suarez, P. A. Z.; de Souza, R. F.; Dupont, J.; Polym. Bull. 1998, 40, 401 .
200. Magna, L.; Chauvin, Y.; Niccolai, G. P.; Basset, J. M.; Organometallics 2003, 22, 4418.
Received: January 9, 2007

Web Release Date: March 28, 2008 